\title{
Bacterial flagella disrupt host cell membranes and interact with cytoskeletal components
}

Eliza. B. Wolfson ${ }^{1 *}$, Johanna Elvidge ${ }^{1}$, Amin Tahoun ${ }^{1,2}$, Trudi Gillespie ${ }^{3}$, Judith Mantell ${ }^{4}$, Sean P. McAteer ${ }^{1}$, Yannick Rossez ${ }^{5}$, Edith Paxton ${ }^{1}$, Fiona Lane ${ }^{6}$, Darren J. Shaw ${ }^{7}$, Andrew C. Gill 6 , Jo Stevens ${ }^{1}$, Paul Verkade ${ }^{4}$, Ariel Blocker ${ }^{8}$, Arvind Mahajan ${ }^{1}$ and David L. Gally ${ }^{1 *}$.

Divisions of Immunity and Infection ${ }^{1}$, Neurobiology ${ }^{6}$ and Clinical Sciences ${ }^{7}$, The Roslin Institute and R(D)SVS, The University of Edinburgh, Easter Bush, Midlothian, EH25 9RG, UK.

${ }^{2}$ Faculty of Veterinary Medicine, Kafrelsheikh University, 33516 Kafr el-Sheikh, Egypt.

3IMPACT Facility, Centre for Integrative Physiology, University of Edinburgh, Edinburgh, EH8 9XD, UK

Departments of Biochemistry ${ }^{4}$ and Cellular and Molecular Medicine ${ }^{8}$, Biomedical Sciences Building, The University of Bristol, Bristol, BS8 1TD

${ }^{5}$ Génie Enzymatique et Cellulaire, UMR 7025 CNRS, Centre de recherche Royallieu, Sorbonne Universités, Université de Technologie de Compiègne, Compiègne Cedex, France *Corresponding authors: Eliza Wolfson eliza.wolfson@cantab.net Tel: 07730481565.

David Gally david.gally@roslin.ed.ac.uk Tel: 01316519243

Short title: Flagella interact with the host cell membranes

Keywords: Flagella, adherence, Escherichia coli, Salmonella, membrane, cytoskeleton, actin

\begin{abstract}
Bacterial flagella have many established roles beyond swimming motility. Despite clear evidence of flagella-dependent adherence, the specificity of ligands and mechanisms of binding are still debated. In this study, the molecular basis of E. coli O157:H7 and S. Typhimurium flagella binding to epithelial cell cultures was investigated. Flagella interactions with host cell surfaces were intimate and crossed cellular boundaries as demarcated by actin and membrane labelling. SEM revealed flagella disappearing into cellular surfaces and TEM of $S$. Typhiumurium indicated host membrane deformation and disruption in proximity to flagella. Motor mutants of E. coli O157:H7 and S. Typhimurium caused reduced haemolysis compared to wild-type, indicating that membrane disruption was in part due to flagella rotation. Flagella from E. coli $\mathrm{O} 157(\mathrm{H} 7)$, EPEC $0127(\mathrm{H} 6)$, and S. Typhimurium (P1 \& P2 flagella) were shown to bind to purified intracellular components of the actin cytoskeleton and directly increase in vitro actin polymerisation rates.
\end{abstract}




\section{Introduction}

Bacterial flagella are protein organelles predominately associated with movement toward preferred environmental niches (1). They are comprised of a long, hollow, capped filament of polymeric flagellin, connected to a flagella basal body through a hook complex (2). The basal body houses a motor complex that rotates the basal body rod, hook and semi-rigid helical flagella filament, or flagellum, to move the bacterium $(3,4)$. The basal body also contains an adapted type 3 secretion export system that regulates secretion of the different organelle components during flagellum assembly $(5,6)$. Flagellin monomers make up the majority of the flagellum and have a hairpin-like structure with highly conserved associating termini and central variable domains (7). Salmonella enterica serovar Typhimurium can alternately express two flagella types, presumably to help avoid the adaptive immune response; phase-1 (P1) flagella are composed of FliC flagellin, and phase-2 (P2) flagella are composed of FljB flagellin (8). In the stacked flagella filament, the flagellin region exposed on the surface shows little conservation between strains and is used for immunological serotyping, resulting in the ' $\mathrm{H}$-type'. The flagellin termini are stacked inside the filament and drive flagellin polymerisation (9). These more conserved and buried regions are important microbe-associated molecular patterns (MAMPs), which activate Toll-like receptor 5 (TLR5) and NOD-like and CARD domain containing receptor 4 (NLRC4) (10-13).

In peritrichous and monotrichous species, flagella have been shown to sense surfaces and cause a switch from motile to sessile lifestyles, making flagellar adhesion the preliminary step essential for bacterial colonisation (14). More recently, flagellar rotation has been shown to play a role in flagella adherence, surface stiffness sensing and inducing Neutrophil extracellular traps $(15,16)$. However, mechanistic information beyond near-surface swimming is lacking and direct adherence along the filament shaft to cell surface components is poorly defined.

Important zoonotic enteropathogens, enterohaemorrhagic E. coli O157:H7 and Salmonella enterica serovar Typhimurium both express flagella and type 3 secretion systems (T3SSs) but have different intestinal colonisation strategies. T3SSs are structurally related to the flagella basal body and act as molecular needles to inject effector proteins into host cells (17). E. coli 0157:H7 use their T3SSs to inject effector proteins into host intestinal epithelial cells, inducing actin polymerisation and the formation of attaching and effacing lesions (18). This cytoskeletal network modulation allows $E$. coli 0157 to bind very tightly to the surface of host enterocytes while avoiding phagocytosis $(19,20)$. In contrast to E. coli O157:H7, S. Typhimurium translocates T3SS effectors into M-cells, inducing the rearrangement of the actin cytoskeleton into membrane ruffles, leading to bacterial uptake by M-cells or intestinal macrophages (21). E. coli $\mathrm{O} 157: \mathrm{H} 7$ is mainly an extracellular bacterium, but is reliant on both a T3SS and its H7 flagella for cell binding and colonisation of its reservoir host, cattle (22-24). 
Published studies indicate that $\mathrm{H} 7$ flagella bind to mucus and more recent work demonstrated binding of different $E$. coli flagella, including $\mathrm{H} 7$, to ionic phospho- and sulpho-lipids $(25,26)$. In contrast, $S$. Typhimurium is invasive in humans and animals, including cattle and pigs, with invasion being dependent on two different T3SSs (27). However, the significance of flagella expression by $S$. Typhimurium for initial attachment and the identity of potential protein ligands remain inconclusive (2830).

This study takes a closer look at the molecular basis of bacterial flagella adherence to host cells in the context of pathogenic colonisation. We start by looking at actin associated with bacterial flagella when bacteria are in contact with host cells. We observe deformation and disruption of host plasma membranes in proximity to flagella and explore possible consequences of membrane breach. Actin and flagella interactions were confirmed by pull downs, far-Western blotting and in vitro actin polymerisation assays. These data shed some light on the interaction between E. coli $0157: \mathrm{H} 7$ and S. Typhimurium flagella and host cells and point towards the possibility of actin rearrangement and membrane ruffling induced by bacterial flagella.

\section{Results}

Bacterial flagella labelling can be coincident with host F-actin staining

In experimental systems that allow bacteria to come into contact with host cells without centrifugation, co-incidence of flagella and F-actin labelling was routinely detected, 60 minutes post-infection for $E$. coli O157:H7 (Fig. 1A-B, Fig. S1 \& Movie S1) and 20 minutes post-infection for S. Typhimurium (Fig. 1C). For Salmonella, co-incidence of flagella with F-actin staining implied that flagella were not necessarily confined to the Salmonella containing vacuole (SCV) during invasion. It was also possible to observe flagella expressed by extracellular Salmonella co-incident with actin at early infection time points. However, not all flagella that were imaged (bacterially associated or not) were found to be coincident with phalloidin-stained actin (Fig. 1D). Where flagella were coincident with F-actin staining, this followed a striated pattern, consistent with the helical wave of flagella filaments. 

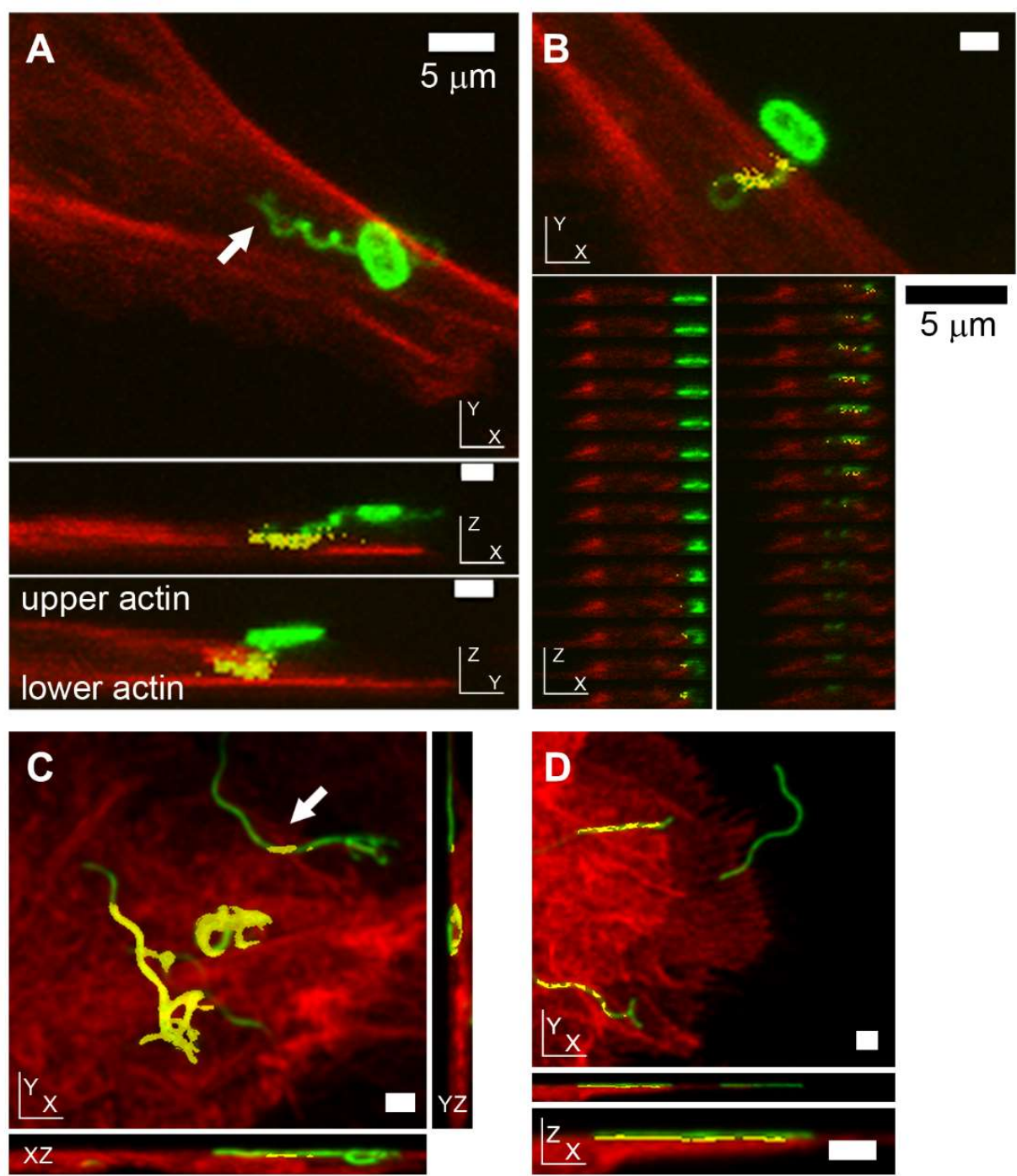

Figure 1. Position of E. coli $0157: \mathrm{H} 7$ and $S$. Typhimurium flagella relative to host cell F-actin during early colonisation by confocal microscopy. Phalloidin-labelled actin is red, antibody-labelled LPS and flagella are green, coincidence of the two is yellow. (A-B) Confocal micrographs of $E$. coli 0157:H7 (TUV93-0) interacting with primary bovine epithelial cell cultures, $1 \mathrm{~h}$ post-infection. (A) Interaction of $E$. coli $\mathrm{O} 157: \mathrm{H} 7$ with host actin with its $\mathrm{H} 7$ flagellum in $\mathrm{XY}, \mathrm{XZ}$ and $\mathrm{YZ}$ projections (3D rotating image in Movie S1, individual Z-slices of $X Z$ and $Y Z$ projections are presented in Fig. S1). (B) Co-incidence of phalloidin-stained actin with an $E$. coli O157-associated coiled $\mathrm{H} 7$ flagellum, but not with the bacterium itself, by $X Y$ projection, with individual $X Z$ slices shown beneath. (C-D) Confocal micrographs of O4:P2 stained S. Typhimurium (SL1344) interacting with IPEC-J2 cells, 20 min post infection. (C) $X Y$ and orthogonal projections of a 3D micrograph where a flagellum emanating from a non-invasive bacterium coincident with actin staining is indicated by an arrow. (D) XY projection of a 3D confocal micrograph of P2 flagella (green) adhering to the cell surface. Not all P2 flagella are coincident with actin, but where there is co-incidence, it is periodic. All samples were fixed with $4 \%$ $(\mathrm{w} / \mathrm{v})$ paraformaldehyde for $>20 \mathrm{~min}$ prior to permeabilisation. Scale bars $=1 \mu \mathrm{m}$ unless indicated. 
Bacterial flagella labelling is intermittently masked by membranes

Coincidence of bacterial flagella with F-actin staining was detected after fixation with $4 \%$ (w/v) PFA then permeabilisation with $0.1 \%(w / v)$ Triton X-100 (Tx100). To observe whether Tx100 treatment altered flagella labelling, confocal microscopy was carried out on GFP-expressing E. coli O157:H7 and S. Typhimurium SL1344 colonised epithelial cells. Cells were fixed and then flagella were labelled with specific antibodies before (red) and after (green) Tx100 treatment. F-actin was then labelled with AlexaFluor647 phalloidin (blue, Methods). Cell-associated flagellated S. Typhimurium and E. coli were imaged in 3D-stacks and representative projections are presented in figure 2. Pre-permeabilisation staining of flagella was often interrupted or less intense in short portions of the flagella, where postpermeabilisation staining of the same flagella was relatively even (Fig. 2). This indicates that bacterial flagella were intermittently masked by a detergent sensitive component during initial stages of infection.

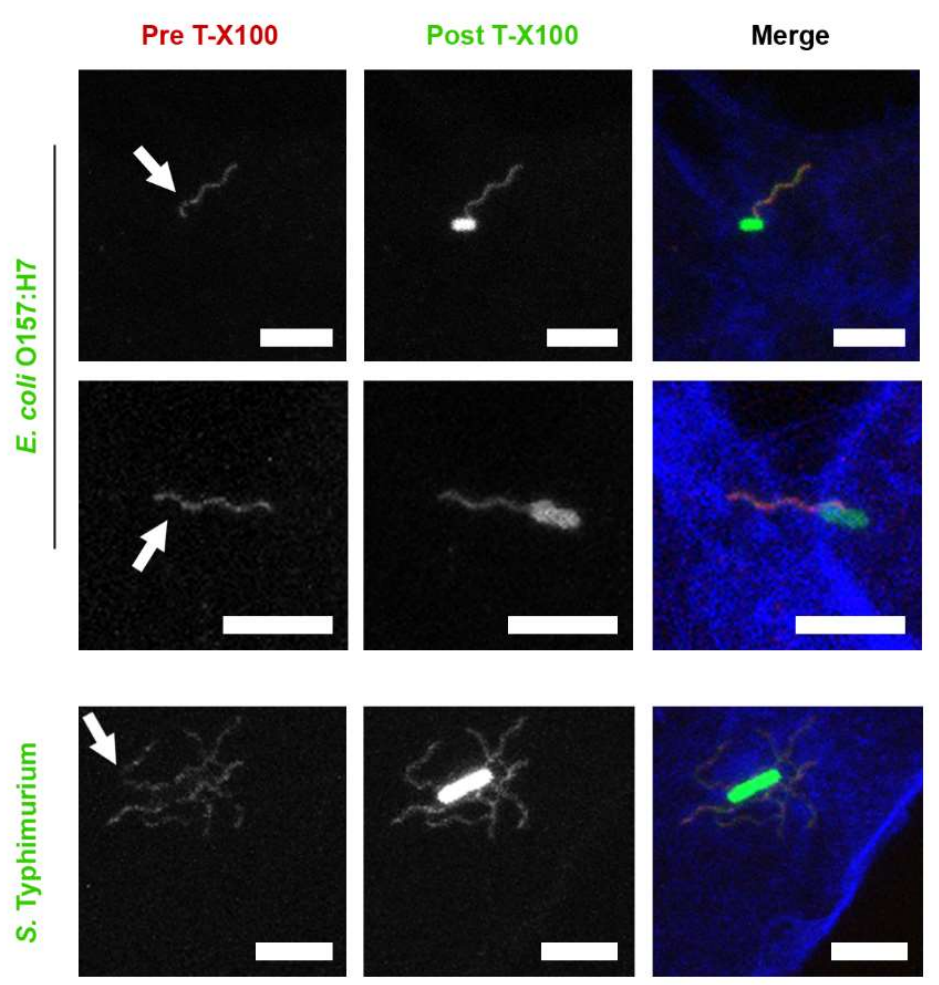

Figure 2. Confocal microscopy of E. coli 0157:H7 and S. Typhimurium flagella staining before and after Triton X-100 treatment. E. coli O157:H7 TUV93-0::pAJR145 (constitutively expressing GFP) interacting with EBL epithelial cells for $1 \mathrm{~h}$, and S. Typhimurium SL1344::pAJR145 interacting with IPEC-J2 epithelial cells for $20 \mathrm{~min}$ before fixation with $4 \%(\mathrm{w} / \mathrm{v})$ paraformaldehyde for $>20 \mathrm{~min}$. Prior to permeabilisation, flagella were labelled with antibodies (red). After permeabilisation with $0.1 \%(\mathrm{v} / \mathrm{v})$ Triton X-100 for $30 \mathrm{~s}$, flagella were labelled with antibodies again (green). Cells were labelled with phalloidin-AlexaFluor647 (blue). Scale bars $=5 \mu \mathrm{m}$. 


\section{Bacterial flagella are detectable on both sides of host cell membranes}

To investigate how close flagella associations with host cell surfaces might be, flagellated adherent $E$. coli O157:H7 and S. Typhimurium were imaged in the context of plasma membrane labelling. For $E$. coli O157:H7 infections, HEK293 cells were transiently transfected with a trans-membrane voltagegated ion channel fusion protein. This ion channel contains a green fluorescent protein (GFP) in the Cterminal cytoplasmic domain. The fluorescent signal generated reports the position of the internal cytoplasmic face of the plasma membrane only (31). $\mathrm{H} 7$ flagella were imaged passing in and out of the GFP-labelled cytoplasmic face of the plasma membrane (Fig. 3A, 3C). Volumetric 3D reconstruction of the labelling in these confocal microscopy images allowed the visualization of transverse sections, showing $\mathrm{H} 7$ flagella labelling within the cell cytoplasmic boundaries (Fig. 3B, 3D).

In contrast, wheat-germ agglutinin binds to the external sugar coated surface of epithelial cell membranes (32). Confocal microscopy of eukaryotic plasma membranes, labelled with fluorescent wheat-germ agglutinin after $S$. Typhimurium infection but before fixation, revealed flagella bundles of invasive S. Typhimurium passing through regions of plasma membrane staining (Fig. 3E). Flagella were observed passing both from inside-to-outside and outside-to-inside host cell areas. Both $E$. coli O157:H7 and S. Typhimurium flagella were observed passing through cellular boundaries by confocal microscopy. 

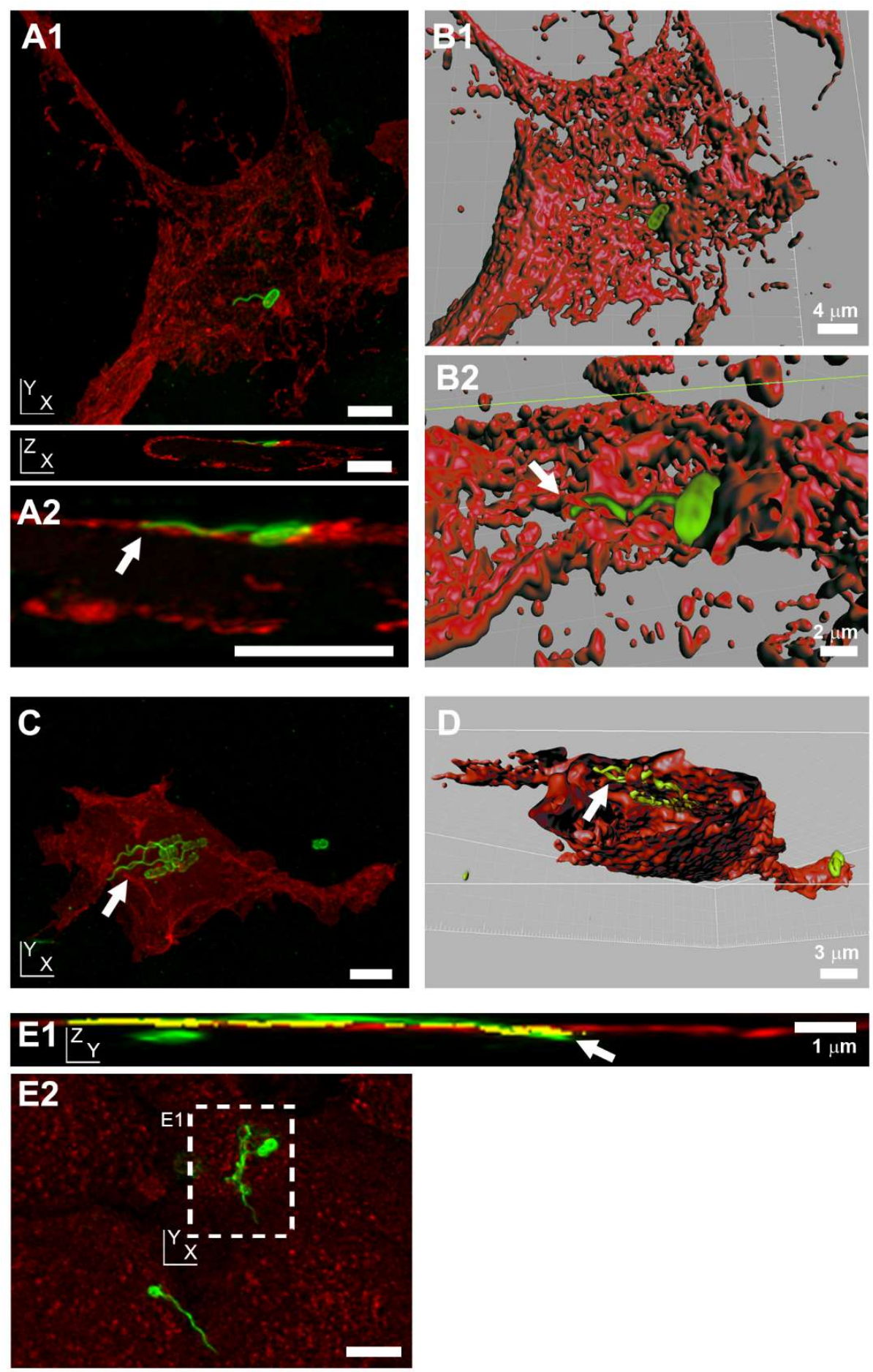

Figure 3. Position of E. coli 0157:H7 and $S$. Typhimurium flagella relative to host cell membranes by confocal microscopy. (A and C) Projections of 3D confocal micrographs of $E$. coli 0157:H7 (TUV93-0: LPS and flagella are green) interacting with HEK293 cells transiently transfected with a transmembrane protein-fluorescent protein fusion construct (red, Materials and Methods) $1.5 \mathrm{~h}$ post infection. This transfection causes labelling of the cytoplasmic face of the plasma membrane cytosolic leaflet (31). (B and $D) 3 D$ volume rendered model of images in (A) and (C) respectively, using Velocity Visualisation software. Arrows indicate intracellular flagella. (A1) $X Y$ and $X Z$ projections of a single flagellum emanating from a bacterium on a transfected HEK293 cell, 3D rendered in (B1) and enlarged in (A2). A similar view has been $3 D$ rendered in (B2), where the arrow indicates intracellular flagella. (C) $X Y$ projection of the binding of a cluster of bacteria expressing $\mathrm{H} 7$ flagella to a transfected HEK293 cell. (D) Transverse cut-through of the HEK293 cell, with flagella visible beneath the layer defined by the cytoplasmic staining of the labelled ion channel protein (arrow). (E) Projections of a 3D confocal micrograph of $\mathrm{O} 4: \mathrm{P} 2$ stained $S$. Typhimurium SL1344 (green) interacting with wheat-germ agglutinin labelled IPEC-J2 cells (red), $10 \mathrm{~min}$ post-infection. This

labelling stains $\mathrm{N}$-acetylglucosamine and sialic acid moieties on the external face of cell membranes (32). (E1) YZ projection of the $X Y$ inset labelled in (E2), with a long flagella bundle that passes out then back into the cell (arrow). Coincidence of flagella and membrane staining is shown in yellow. (E2) XY projection of whole image shown in (E1). All samples were fixed in $4 \%(\mathrm{w} / \mathrm{v})$ para-formaldehyde for $>20 \mathrm{~min}$ prior to permeabilisation. Scale bars $=5 \mu \mathrm{m}$ unless indicated. 
Defining bacterial flagella interactions with host cell membranes by electron microscopy

The z-plane resolution limit of confocal laser scanning microscopy is $\sim 500 \mathrm{~nm}$ with the fluorophores used, but host cell plasma membranes are only $\sim 5 \mathrm{~nm}$ thick. 0157:H7 immuno-gold scanning electron microscopy (SEM) was used to take a closer look at $\mathrm{H} 7$ flagella interactions with host cell surfaces without Tx100 treatment. As with confocal microscopy of pre-permeabilisation labelling, E. coli O157:H7 flagella immune-gold staining was interrupted as the filament disappeared into the primary intestinal epithelial cell surface, then resumed as it curled upwards away from the surface (Fig. 4A-B). SEM of $S$. Typhimurium at early time points of infection (10-30 min, again without Tx100 treatment), also revealed flagella-like filaments interacting intimately with cell surfaces of primary intestinal epithelial cells by SEM (Fig. 4C). These filaments could be seen disappearing and reappearing from the cell surface, consistent with actin coincidence observed by confocal microscopy. $S$. Typhimurium flagella-like filaments were also observed associating with membrane ruffles and protrusions during the invasion process (Fig. 4DE).

These observations were made with serologically and structurally distinct flagella (Fig. S2), hinting that a biophysical mechanism may be involved. To look for evidence of biophysical interactions of flagella with host cell membranes, $S$. Typhimurium flagella closely associated with host cells were located with correlative light and electron microscopy and examined by thick-section transmission electron tomography (Fig. 5). To preserve the details and visibility of the host cell membranes, conventional post section staining of flagella was not undertaken, but the visibility of the structures in the tomogram slices was enhanced by applying an anisotropic diffusion filter and a blue-orange ICB colour lookup table in Amira software. 

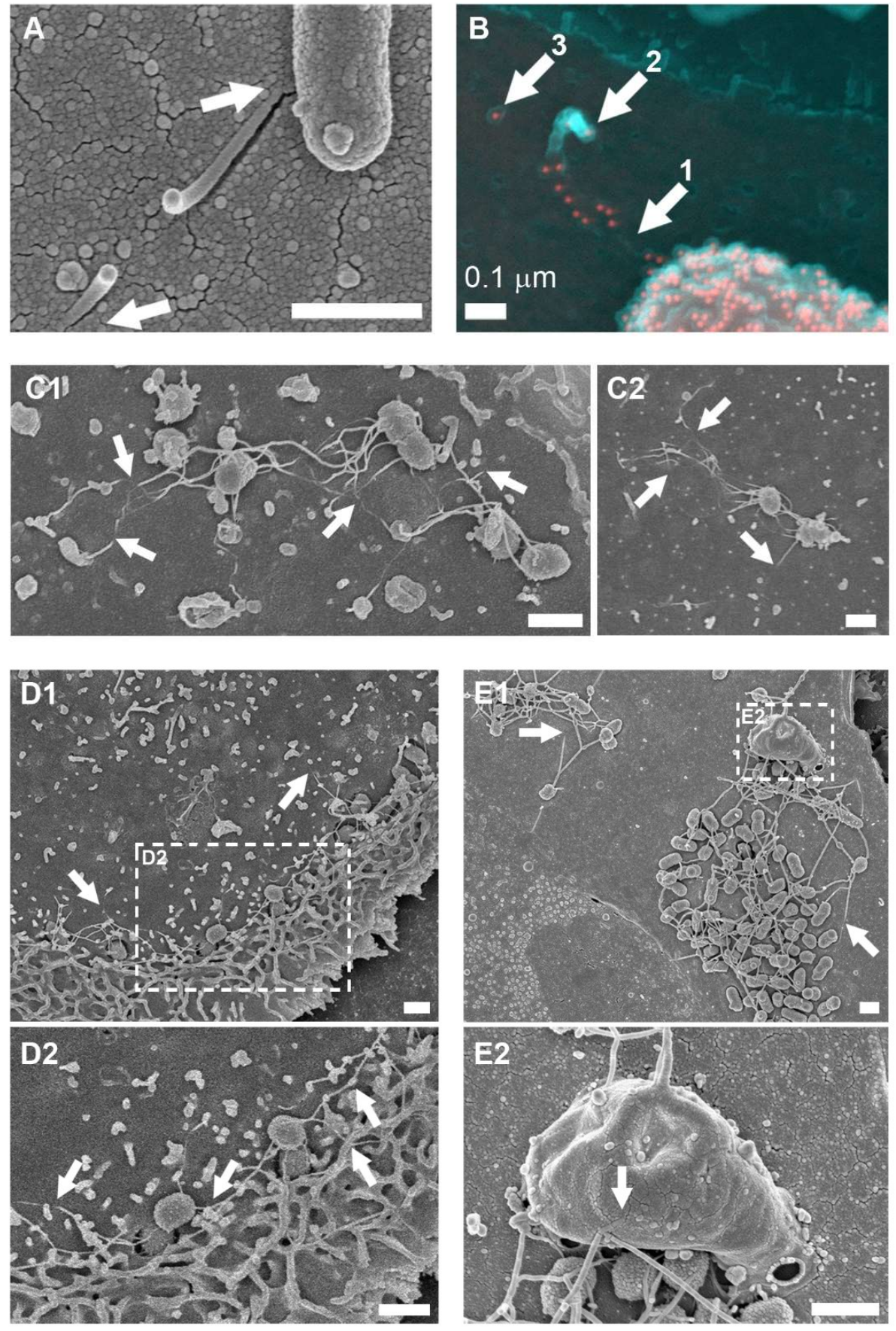

Figure 4. Scanning electron microscopy of E. coli 0157:H7 and $S$. Typhimurium flagellalike structures disappearing and reappearing at host cell surfaces. (A-B) E. coli O157:H7 (ZAP734) interactions with bovine primary epithelial cell cultures, $3 \mathrm{~h}$ post-infection. (A) Secondary electron (SE) image of a snapped flagella-like filament, which appears to penetrate the cell surface (arrows). (B) shows a false coloured SE image (cyan) superimposed with false coloured back-scattered image (red). H7 flagella and 0157 LPS are both immuno-gold labelled. Filament staining occurs adjacent to the bacterium and is then absent (arrow 1). The filament is then broken and curls back on itself (arrow 2), with the remnant embedded filament (arrow 3). (C1-C2) SE images of flagellalike filaments disappearing into and coming out of the surface of IPEC-J2 epithelial cells (arrows), within the first thirty minutes of infection with $S$. Typhimurium (Maskan). (D) SE image of $S$. Typhimurium (Maskan) microcolonies on IPEC-J2 cells, 40 min post-infection. (D1) shows actin ruffling proximal to invading Salmonella. (D2) is enlarged from the inset indicated in D1. Wavy flagella-like filaments are interacting with ruffled and un-ruffled cell surfaces (arrows). (E) SE image of $S$. Typhimurium SL1344 (WT) micro-colonies on bovine primary epithelial cells. (E1) shows long filaments disappearing into the cell surface (arrows). (E2) is a higher resolution image of the area indicated in B1, which shows long filaments interacting with a large macropinocytic protrusion (arrow). Samples were fixed in $3 \%$ $(\mathrm{w} / \mathrm{v})$ glutaraldehyde and were not permeabilised prior to sample processing for scanning electron microscopy. Imaging was undertaken on a Hitachi 4700 Field Emission Scanning Electron microscope. Scale bars $=1 \mu \mathrm{m}$ unless indicated. 

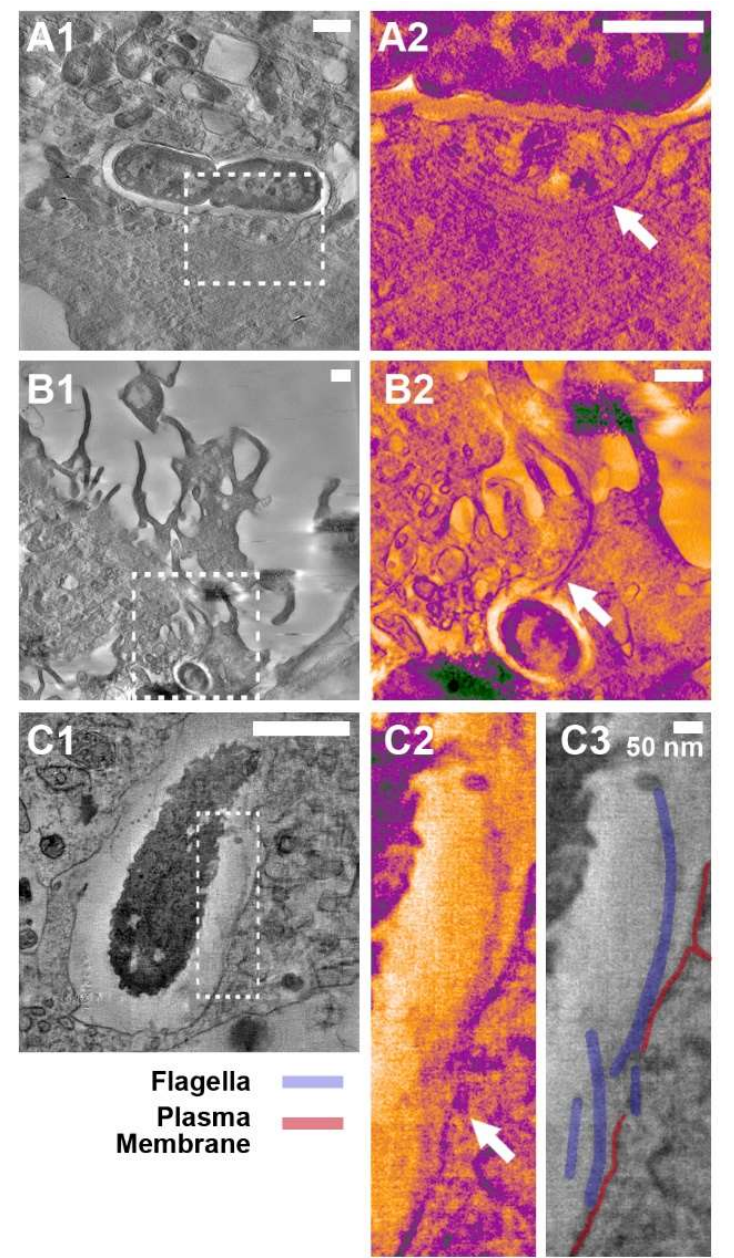

Figure 5. Electron tomography of host cell membranes in proximity to $S$. Typhimurium flagella-like structures. S. Typhimurium SL1344:::PAJR145 interacting with IPEC-J2 cells, 20 $\min$ post infection. Fixation with $4 \% \quad(w / v)$ paraformaldehyde was undertaken for $>20$ min prior to flagella labelling and samples were not treated with any detergents. Confocal microscopy was used to locate bacteria with flagella in contact with host cells and correlative electron tomography was undertaken (Methods). The contrast of insets was enhanced using the blue_orange_ICB look up table in Fiji software. (A1) Flagellated S. Typhimurium within an epithelial cell. (A2) Inset in A1; the flagella cross the gross vacuole boundary but are present inside an intact membrane channel (arrow). (B1) Flagellated $S$. Typhimurium inside a membrane ruffle. (B2) Inset in B1; the flagella bundle passes through the gross boundaries of the ruffle but is adjacent to a distinct membrane boundary (arrow). (C1) Flagellated $S$. Typhimurium at the point of induced uptake into an epithelial cell. (C2) Inset in C1; flagella in proximity to the disrupted epithelial plasma membrane (arrow). (C3) Structures in C2 are labelled for clarity. Scale bars $=500 \mathrm{~nm}$ unless indicated.

Host cell membranes were observed encapsulating bundles of flagella filaments during the $S$. Typhimurium invasion process (Fig. 5A-B, Movies S2-3). Consistent with previous microscopy, these flagella were located within gross cellular boundaries at points, but they were separated from the host cytosol by deformed but contiguous host membranes. Visually distinct from these observations, was the reduction or interruption of clear membrane staining in proximity to bacterial flagella (Fig. 5C, Movie S4). In this example, the flagella filaments are largely accessible to extracellular antibody labelling, as shown by the punctae that occur regularly along their length. Figure $5 \mathrm{C} 2$ shows the labelled bundle of flagella filaments drawing close to a clearly defined plasma membrane, but as they come into presumable contact, the membrane boundary is both deformed and less distinct, and in places apparently absent, suggesting membrane disruption. 


\section{Bacteria with paralysed flagella cause less membrane disruption}

To test whether flagella rotation is capable of causing physical disruption of host cell membranes, sheep red blood cells (RBCs) were used as a model dye-filled eukaryotic plasma membrane, as they contain haem pigment. Short-term incubation of RBCs was undertaken with bacteria and their isogenic flagella and flagella motor (mot) mutants; mot mutants result in the production of full-length flagella that do not rotate. Bacteria were cultured under conditions known to induce expression of flagella and briefly centrifuged into contact with RBCs to eliminate the contribution of motility and chemotaxis to this process (Methods, Fig. 6).

A

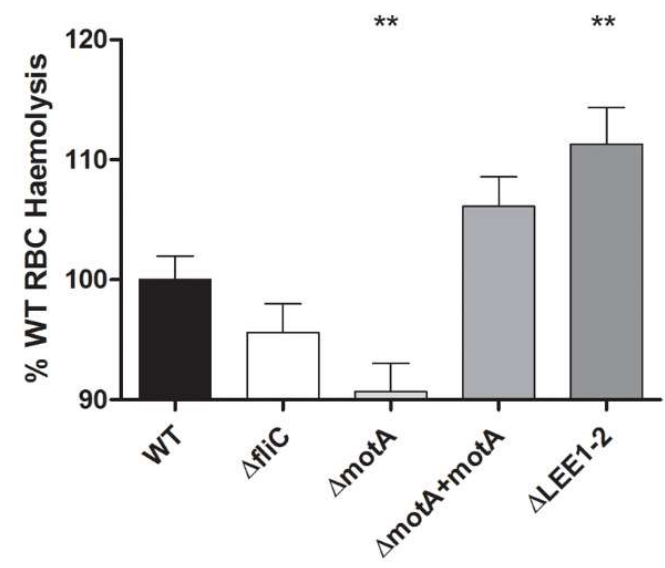

B

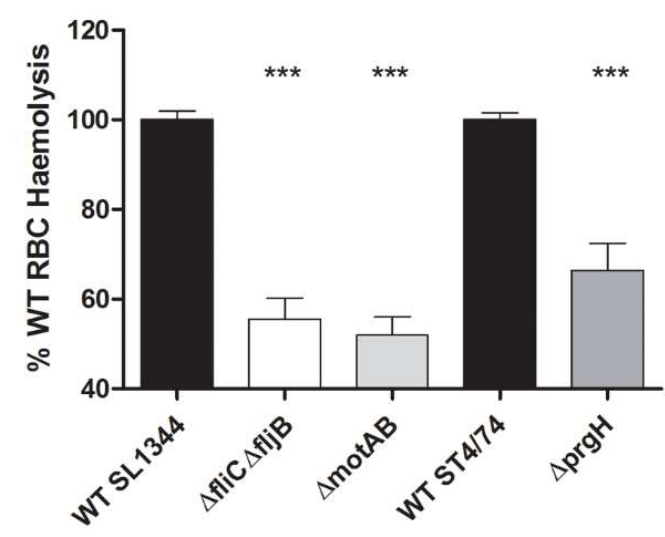

Figure 6. Contribution of flagella rotation to membrane disruption by $S$. Typhimurium and E. coli 0157:H7. Sheep red blood cells (RBCs) were incubated with stationary phase cultures of the E. coli O157:H7 (A) and S. Typhimurium (B) strains indicated for $2 \mathrm{~h}$ at $37^{\circ} \mathrm{C}$, after centrifugation together at $2000 \times \mathrm{g}$ for $5 \mathrm{~min}$ to ensure contact. After incubation, samples were centrifuged at $2000 \times g$ for 10 min and the $A_{405}$ of supernatants were measured. Data from 3-5 biological replicates are presented as \% wild-type (WT) haemolysis and statistical analysis was performed on raw data using 2-tailed homoscedastic student's ttests; $p \leq 0.01\left(^{* *}\right), p \leq 0.001\left(^{* * *}\right)$. The results were considered as significant for a $p$ value $\leq 0.05$.

All flagellate wild-type strains caused membrane disruption upon interaction with RBCs, as determined by haem release. As haem release could be due to the T3SSs of either pathogen, T3SS mutants ( $\Delta \mathrm{prgH}$ for S. Typhimurium, $\Delta$ LEE1-2 for E. coli O157:H7, Table 1) were tested under these flagella-selective 
growth conditions (Fig. 6). Mutation of T3SSs resulted in altered mean levels of haem release compared to wild-type for both S. Typhimurium ( 30\% reduction) and E. coli O157:H7 ( 10\% increase). Both effects were statistically significant $(p<0.0001$ and 0.0039 respectively), suggesting that the T3SSs were directly involved in haem release.

Mutation of flagella and flagella rotation caused reduced mean levels of haem release for both $S$. Typhimurium and E. coli O157:H7. For S. Typhimurium, the levels of haem release were approximately half of wild-type in both flagellin $(\triangle f l i C \Delta f l j B)$ and motility $(\triangle m o t A B)$ mutants, with statistically significant values ( $p<0.0001$ for both, Fig. 6). For wild-type E. coli O157:H7, mean levels of haem release were much less affected by flagellin ( $\mathrm{FliC}^{-}$) and motor ( mot $^{-}$) mutation. Reductions of $\sim 5 \%$ for fliC' were not statistically significant $\left(p=0.17\right.$ ). In contrast, a reduction of $\sim 10 \%$ for $\operatorname{mot} A^{-}$was statistically significant ( $p=0.0046$ ). The subtle effect for $E$. coli $\mathrm{O} 157: \mathrm{H} 7$ may reflect the lower overall flagella expression, lower rotation speeds and motility of E. coli wild-type compared to Salmonella (Fig. S3, (33, 34)). These results suggest that the flagella of $S$. Typhimurium and $E$. coli $0157: \mathrm{H} 7$ are physically able to disrupt eukaryotic plasma membranes, but with different efficacies, and flagellar rotation is likely to play a key role.

Bacterial flagella can interact with components of the actin cytoskeleton in vitro

If bacterial flagella can disrupt host cell membranes, perhaps they are also able to interact with cytosolic components just beneath host cell membranes. Initial pull downs and far-Western blotting with $\mathrm{H} 7$ flagella identified $\beta$-actin (ACTB1), cofilin-1 (CFL1) and galectin-4 (GAL4) as potential interactants (Fig. S4). A 'far' ELISA was designed to assess relative flagella binding to human $\beta \gamma$-actin, recombinant human CFL1 and recombinant human GAL4. These purified proteins were coated to 96-well plates, probed with 1000-100 ng flagellins, then binding was detected using appropriate antibodies. Binding data were normalized to negative (no flagellin added) and positive (wells coated with $1 \mu \mathrm{g}$ flagellin) detection controls to give a measure of relative binding (Methods). Binding of polymeric and monomeric flagellin from E. coli O127:H6, E. coli O157:H7, commensal E. coli K12:O175:H48 and S. Typhimurium $\mathrm{O} 4: \mathrm{Hi} / \mathrm{H} 2$ expressing either $\mathrm{P} 1$ or P2 flagella was assessed (Fig. 7, S2). 


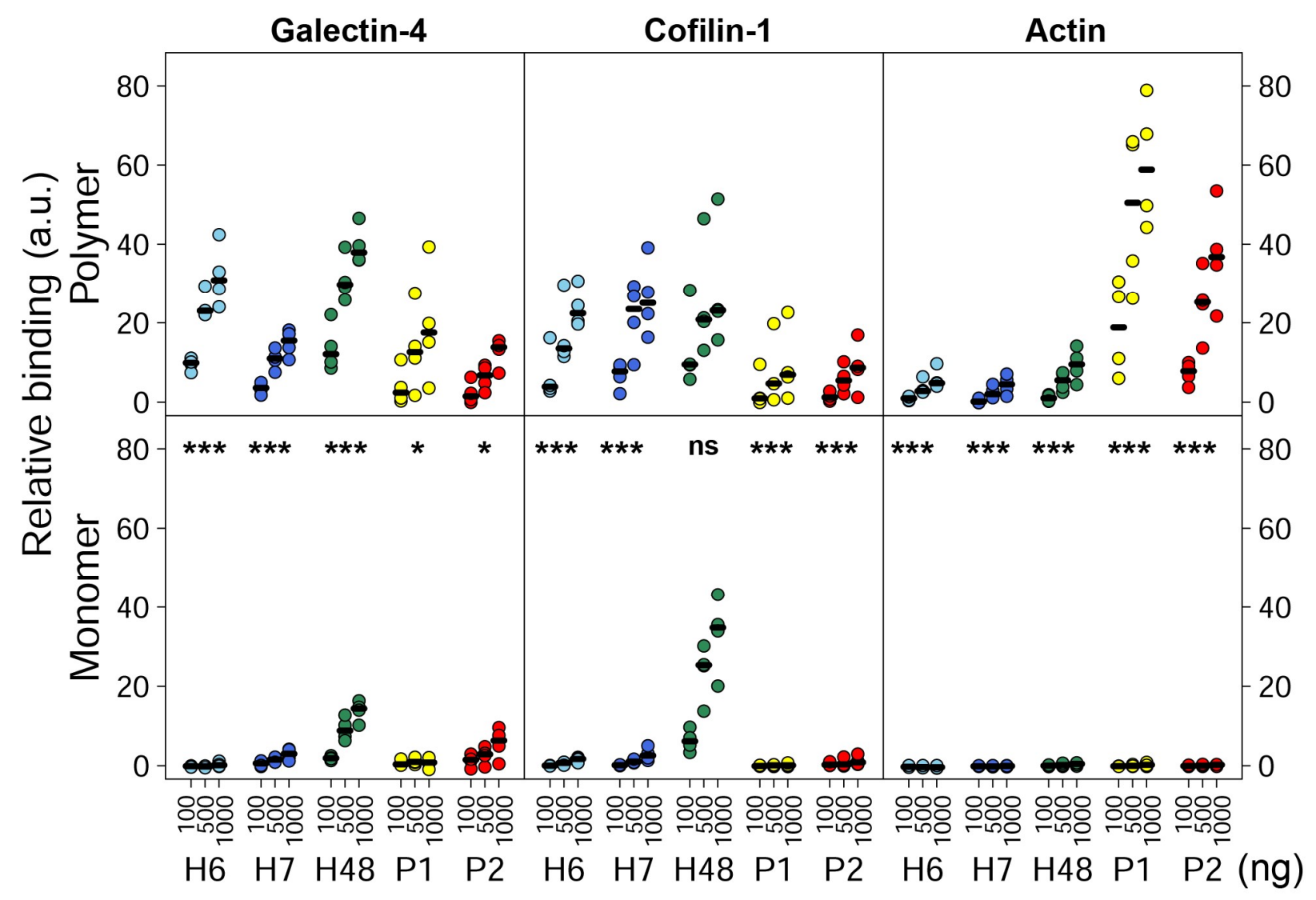

Figure 7. Relative binding of flagella from E. coli and S. Typhimurium to cytoskeletal proteins by far-ELISA. Flagella binding interactions with identified cellular components assessed by far-ELISA. Binding of 100, 500 and 1000 ng/well of polymeric and monomeric H6 (light blue), H7 (dark blue) and $\mathrm{H} 48$ flagella (green) from E. coli, and P1 (yellow) or P2 (red) flagella from S. Typhimurium to 1000 $\mathrm{ng} /$ well galectin-4, cofilin-1 and $\beta \gamma$-actin. Median values of four independent experiments are indicated with black horizontal lines. Relative binding levels are shown as data are normalised to positive and negative detection controls for each antibody and protein pair (Methods). Statistical analyses presented are pairwise comparisons of polymer and monomer using linear mixed effects models; ns, not significant, $p \leq 0.01\left(^{*}\right), p \leq 0.0001\left(^{* * *}\right)$.

For all interactions tested, except for H48-CFL1 $(p=0.55)$, monomeric flagellins bound at significantly lower levels than polymeric flagellins (Fig. $7, p=0.0023-0.0001$ or less, depending on the flagellin tested), serving as a suitable baseline for non-binding in this assay. This was particularly the case for the actin interactions, where binding by flagellin monomers was virtually undetectable in this assay for each flagellin type tested. 
There were different patterns of binding between $E$. coli and S. Typhimurium polymeric flagellins; $E$. coli flagellins showed higher relative binding to CFL1 compared to $\beta \gamma$-actin under these conditions, and conversely the $S$. Typhimurium flagellins tested showed a stronger association with $\beta \gamma$-actin, compared to CFL1. All polymeric flagellins tested bound to GAL4, though there was no particular distinction between S. Typhimurium and E. coli relative levels. Binding to GAL4 was not a consequence of flagella post-translational glycosylation; determination of molecular weights by mass spectrometry of $\mathrm{H} 6$ and $\mathrm{H} 7$ sheared preparations indicated that these flagellins were unmodified, whilst modified forms of $S$. Typhimurium flagellins were consistent with methylation (data not shown, (35)).

\section{Bacterial flagella can increase actin polymerisation rates in vitro}

To further confirm the in vitro binding interactions of $\mathrm{H} 6, \mathrm{H} 7, \mathrm{P} 1$ and $\mathrm{P} 2$ polymeric flagellin with actin, their effect on actin polymerisation was assessed (Fig. 8A). $1 \mathrm{mM}$ pyrene-conjugated rabbit $\alpha \beta$-actin in $10 \mathrm{mM}$ Tris- $\mathrm{HCl}, 200 \mu \mathrm{M} \mathrm{CaCl}_{2}, 200 \mu \mathrm{M}$ ATP, $1 \mathrm{mM}$ DTT, $\mathrm{pH}$ 7.5, was used as a baseline (Actin control). Actin polymerisation was initiated by addition of final concentrations of $5 \mathrm{mM} \mathrm{KCl}, 0.2 \mathrm{mM}$ $\mathrm{MgCl}_{2}$ and $0.1 \mathrm{mM}$ ATP (Actin). The actin severing activity of CFL1 at 2:1 ratio with actin generates more rapidly polymerising 'plus' ends of actin (36), so $500 \mathrm{nM} \mathrm{CFL1} \mathrm{was} \mathrm{added} \mathrm{as} \mathrm{a} \mathrm{positive} \mathrm{control}$ for enhanced rates of actin polymerisation (cofilin-1). The bacterial flagella filaments tested all enhanced in vitro rabbit $\alpha \beta$-actin polymerisation to variable extents, implying a direct interaction with physiologically active actin (Fig. 8A). Higher median actin polymerisation $\mathrm{V}_{\max }$ rates were determined for all flagella tested when compared to actin alone, with P2 flagella showing a statistically significant dose-dependent effect $(p=0.003$, Fig $8 A-B)$.

To investigate whether $\mathrm{H} 6$ and $\mathrm{H} 7$ flagella interactions with $\mathrm{CFL} 1$ enhanced the effect they had on actin polymerisation, $\alpha \beta$-actin was co-incubated with the four flagella types and two different concentrations of CFL1 (Fig. 8C). Without CFL1, $250 \mathrm{nM}$ of each flagella type was sufficient to cause a statistically significant increase in the $\mathrm{V}_{\max }$ of actin polymerisation, with $\mathrm{S}$. Typhiumurium $\mathrm{P} 2$ flagella being the most effective. This low concentration of flagella was chosen to allow detection of increases in actin polymerisation rates that may occur as a result of synergy between flagella and CFL1 interactions. Adding an equimolar concentration of CFL1 (250 nM) caused a trend towards further enhanced rates of actin polymerisation, but this was not statistically different to addition of CFL1 alone for any of the flagella types tested ( $p=0.124-0.856$ ). At a 2:1 molar concentration of CFL1:flagella, at which the CFL1 concentration was optimal, further increases in the $\mathrm{V}_{\max }$ of actin polymerisation were apparent for all flagella tested. These increases were only statistically significant with P1 and P2 flagella, compared to the effect of CFL1 alone ( $p=0.035$ and 0.004 respectively). Additionally, there was no statistically significant interaction between CFL1 concentration and flagella type ( $p=0.6$, Methods), indicating that 
the effects on $V_{\max }$ were additive and not due to any synergistic effects of flagella and CFL1 on actin polymerisation.

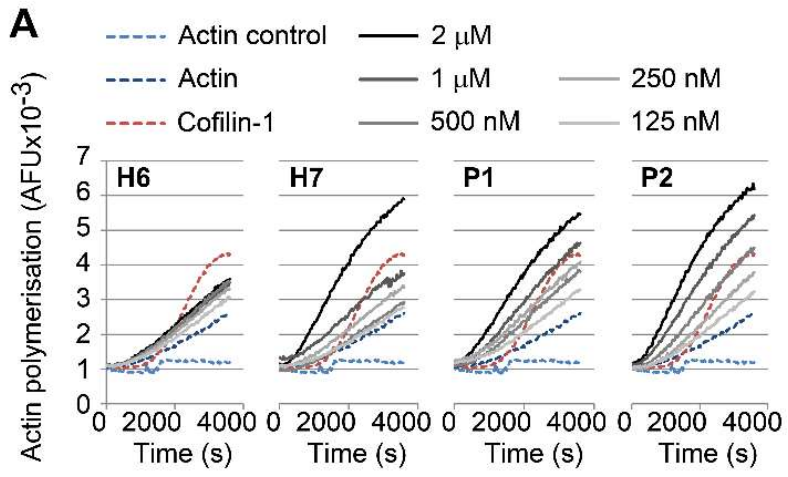

B

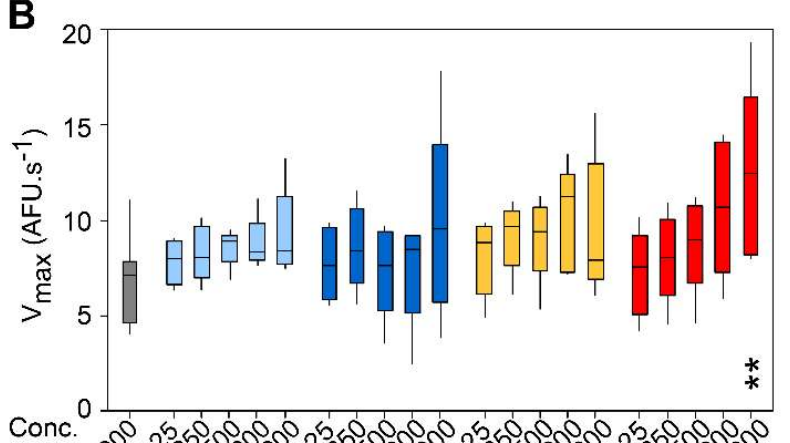

(nM) 100 , น
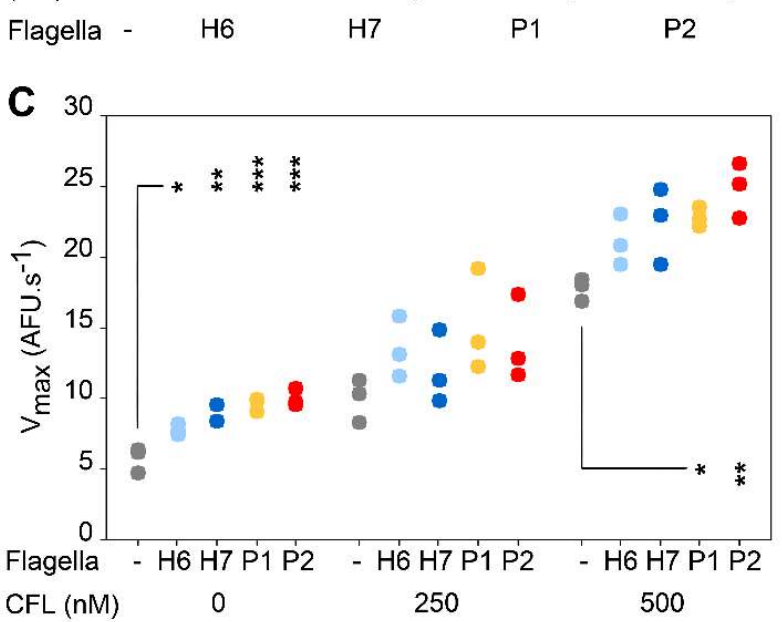

Figure 8. Impact of flagella type on actin polymerisation kinetics. (A) Effects of $\mathrm{H} 6, \mathrm{H} 7, \mathrm{P} 1$ and $\mathrm{P} 2$ flagella on $\alpha \beta$-actin polymerisation. Pyrene-conjugated globular (G)-actin polymerisation was triggered by addition of $5 \mathrm{mM} \mathrm{KCl}, 0.2 \mathrm{mM}$ $\mathrm{MgCl}_{2}$ and $0.1 \mathrm{mM} \mathrm{ATP}$ in the presence of different concentrations of flagella, and arbitrary fluorescence (AFU) was measured every $30 \mathrm{~s}$ for $1 \mathrm{~h}$ at RT. $500 \mathrm{nM}$ cofilin-1 (CFL) was used as a positive control for increased actin polymerisation rates in sub-optimal conditions (37). Data shown is a representative experiment. (B) Maximum velocity $\left(\mathrm{V}_{\max }\right)$ of actin polymerisation in the presence of titrating concentrations ( $125 \mathrm{nM}-2 \mu \mathrm{M}$ ) of $\mathrm{H} 6$ (light blue), $\mathrm{H} 7$ (dark blue), P1 (yellow) and P2 (red) flagella. Data was analysed from five independent experiments and post-hoc Tukey pairwise comparisons of differences between specific flagella concentrations and actin alone are presented; $p<0.01{ }^{* *}$. (C) $V_{\max }$ of actin polymerisation in the presence of $250 \mathrm{nM} \mathrm{H} 6, \mathrm{H} 7, \mathrm{P} 1$ and P2 flagella, and sub-optimal (250 nM) and optimal $(500 \mathrm{nM})$ concentrations of cofilin1 (CFL). Data represents results from three independent experiments and posthoc Tukey pairwise comparisons of the difference between CFL with and without different types of flagella are presented; $p<0.05\left(^{*}\right), p \leq 0.01\left(^{* *}\right), p \leq 0.001\left(^{* * *}\right)$. 


\section{Discussion}

We have known for some time now that bacterial flagella are more than just motility organelles. The idea of flagella as a long adherence organelle for early host surface attachment by commensal and pathogenic bacteria alike is now widely accepted. This raises the question of why there are so few published examples of specific cell-surface protein receptors for flagella.

This paper presents the masking of Salmonella and E. coli flagella antigens by a detergent-sensitive component, which indicates very intimate interactions of these flagella with host cell lipids. Such a close interaction between flagella and membranes was borne out by confocal microscopy of membrane labelled samples. Additionally, flagella of S. Typhimurium and E. coli O157:H7 have been shown to bind to cholesterol and ionic sulpho- and phospho-lipids in vitro respectively $(26,38)$, so it is conceivable that these flagella could be binding directly to plasma membranes.

Several studies attribute flagella-mediated adherence to surfaces as largely biophysical processes. It has been demonstrated that $E$. coli $\mathrm{H} 48$ flagella are generally attracted to hydrophobic surfaces and are ten times more likely than the bacterial cell body to make contact with artificial surfaces. These collisions by flagella with hydrophobic abiotic surfaces are known to slow bacteria down, promoting adhesion $(39,40)$. This is also true in near surface swimming, a biophysical process dependent on rotating flagella, which has been shown to aid cooperative colonisation by probing and facilitating docking at membrane protrusions $(41,42)$. Additionally, the structural properties of different flagellin phase types have been shown to alter $S$. Typhimurium flagella rotation and near-surface swimming behaviour, with downstream effects on colonisation (43).

The observations of flagella crossing gross cellular boundaries presented here raise the possibility that flagella-mediated adherence may go beyond surface adhesion. This was routinely detected by confocal microscopy of actin and membrane labelled samples. Such overlaps could be explained by insufficient resolution of cellular boundaries, and electron tomography showed this to be at least partially the case. Flagella bundles attached to colonising bacteria were observed crossing gross cellular boundaries, but the majority remained enclosed within deformed membrane channels. This hints that biophysical membrane deformation by flagella may enhance host membrane ruffling, aiding flagella dependent adherence by creating favourable surface topologies for membrane binding. Where possible membrane disruption was observed, cells were fixed for microscopy, so there is the potential for observation artefacts resulting from sample dehydration. However, at the time of writing, the technology to obtain 3D sub-micrometre resolution of moving samples, labelled in a way that will not interfere with interacting surfaces, is not readily available. Nevertheless, the observations are supported by the additional 
phenotypic data that E. coli $\mathrm{O} 157: \mathrm{H} 7$ and $S$. Typhimurium cause $10 \%$ and $50 \%$ respectively less disruption of biological membranes without flagella rotation, compared to wild-type.

Where potential disruption of host cell membranes in proximity to bacterial flagella was observed by electron tomography, the mechanism by which they do this remains speculative. The haemolysis data supports a role for flagella rotation. Yet whether this membrane disruption is direct, due to biophysical force, or indirect, due to increased probabilities of favourably charged flagella colliding with membranes, is not known. Alternatively, on epithelial cells this process could be a consequence of pathogen-induced large-scale membrane rearrangements seen during $S$. Typhimurium and $E$. coli colonisation, trapping flagella at random, or directed by receptor-mediated endocytosis, triggered by flagella binding to relevant surface molecules. $P$. aeruginosa flagella bind to MUC1 and heparin-sulphated proteoglycans and E. coli flagella bind to ganglioside receptor GM1 and charged glycerolipids, resulting in immunomodulation and invasion $(26,44-46)$. It is also possible that membrane penetration could be caused by a combination of these factors.

Interaction with actin cytoskeletal proteins was not restricted to flagella from pathogenic bacteria. As established, the predicted surface epitopes of the different polymerised flagellins studied are markedly distinct (Fig. S2), complicating analyses of key surface regions required for CFL1, galectin-4 and $\beta \gamma$ actin binding. Friedlander et al. (42) proposed that flagella binding to artificial surfaces involves lowaffinity but high-avidity co-operative binding to surface substrates. Multiple low-affinity interactions of the different polymeric flagellins may also account for the direct binding to cytoskeletal proteins observed in the present study. This supports the concept that this co-operative binding of flagellin subunits within a filament is a generic property of flagella. In a pathogenic context this could lend itself to binding repetitive substrates like actin filaments. Flagella in a non-pathogenic context may be capable of binding to actin and actin binding proteins, but for this to be relevant, the flagella would have to gain access through the mucus layer to the epithelial surface. Conversely, motility and flagella-deficient strains of $E$. coli and $S$. Typhimurium can still be pathogenic $(47,48)$. However, where expressed, the importance of flagella in colonisation of enteropathogenic and enterohaemorrhagic $E$. coli, and $S$. Typhimurium has been established $(22,28,43,49)$, and this study highlights another potential reason for this.

Furthermore, a recent paper has identified a proteolytic site in the hypervariable region of flagella, present in at least 74 bacterial species, including several species of Clostridium. This metallopeptidase domain, named flagellinolysin was not found in either E. coli nor S. enterica (50). However, this raises the possibility that these flagella are capable of other enzymatic activities against actin or membrane lipids. Additionally, by using flagellinolysin negative species, this study could serve as a baseline in 
assessing the relative contribution of flagellinolysin to flagella-dependent colonisation processes in the future.

Flagella interactions with actin were undertaken with isolated components in physiological conditions, confirming direct binding. Many pathogens reorganise host actin architecture during host colonisation. The first bacteria described to use actin rearrangement were the intracellular bacteria Listeria monocytogenes and Shigella flexneri $(51,52)$. They both generate filamentous actin "comet tails" that propel the bacteria through the cytosol, allowing colonisation of neighbouring cells. Modulation of actin and actin binding proteins, such as Arp2/3 and CFL1 has also been described for certain pathogenic E. coli and Salmonella spp. secreted effector proteins $(53,54)$. However, the findings in this current study provide the first evidence of potential actin manipulation by bacterial flagella. That flagella may be able to plug into this complex system by itself in standard conditions is intriguing, given the lifestyles of their associated pathogens. Conversely, there was no evidence that the in vitro binding interactions of $\mathrm{H} 7$ flagella with CFL1 affected actin polymerisation synergistically. It is possible that additional factors are required for this; if flagella can gain access to the host cytosol directly, the presence of other actin regulators and different micro-environments may inhibit or enhance these interactions to affect host cell binding or invasion.

In summary, the results of this study demonstrate that S. Typhimurium and E. coli O157:H7 flagella become intimately associated with host cell membranes during initial adherence. This association either results in or is a consequence of host membrane deformation that may cause disruption, with any disruption likely to be a consequence of flagella rotation. S. Typhimurium and E. coli O157:H7 can bind to actin and actin-binding proteins. These interactions can influence cytoskeletal dynamics in vitro and this may be relevant during bacterial colonisation. An understanding of how connected these two phenomena are will require further work to elucidate the molecular mechanisms involved.

\section{Materials and Methods}

\section{Bacterial strains and growth conditions}

Bacterial strains (Table 1) were stored as saturated cultures in Lysogeny Broth (LB) broth with $25 \%$ glycerol at $-70^{\circ} \mathrm{C}$. Bacteria were grown in $\mathrm{LB}$ broth at $28^{\circ} \mathrm{C}-30^{\circ} \mathrm{C}(E$. coli $0157: \mathrm{H} 7)$ or $37^{\circ} \mathrm{C}(\mathrm{S}$. Typhimurium) at $200 \mathrm{rpm}$. Antibiotics when required were chloramphenicol or kanamycin at $50 \mu \mathrm{g} / \mathrm{ml}$ and ampicillin at $100 \mu \mathrm{g} / \mathrm{ml}$. To assess strain motility, fresh colonies were stab-inoculated once into $0.3 \%(\mathrm{w} / \mathrm{v})$ LB agar. Inoculated plates were incubated at room temperature (RT) for $36 \mathrm{~h}$. Assays were carried out in quadruplicate from separate colonies. 


\section{Mutant strain construction}

The flagellin gene $\mathrm{fliC}_{\mathrm{H} 7}$ from the $\mathrm{E}$. coli $\mathrm{O} 157 \mathrm{H}$ 7 strain TUV93-0 was exchanged with $\mathrm{fliC}_{\mathrm{H} 6}$ according to the allelic exchange method published by Blomfield et al. (55). Briefly, homologous recombination of pEBW6 or pEBW7 (Table S1) with TUVAfliC (Table 1) and counter-selection of sacB with sucrose was used to generate TUVAfliC chromosomally complemented with fliC $\mathrm{H}_{\mathrm{H}}$ ( $T U \mathrm{VfliC}_{\mathrm{H} 6 \mathrm{~F}}$ ) and fliC $\mathrm{H}_{\mathrm{H}}$ ( $T U V$ fli $C_{H 7 F}$ ) respectively. Strains were validated by PCR with sacB, fliC locus and $\mathrm{O} 157$ specific primer pairs (Table S2), Sanger sequencing, motility in $0.3 \%(\mathrm{w} / \mathrm{v}) \mathrm{LB}$ agar and wide-field fluorescence microscopy of saturated cultures with 1:1000 dilutions of H6- and H7- specific rabbit IgG (Table S3). The TUV93-0 motA mutant (ZAP1575, Table 1) was constructed by allelic exchange using pTOF25motA (Table S1) and primer sets: No-motA, Ni-motA, Co-motA and Ci-motA (Table S2). The deleted region corresponds to 2653444-2654278 of EDL933 and was verified by sequencing. A chromosomally complemented strain was made (ZAP1576, Table 1) using the amplicon of primers NomotA/Co-motA (Table S2) and cloning and exchange with the resultant pTOF25 construct. This motA complemented version of ZAP1575 has restored motility (Fig. S3). P22 transduction of phase-locked (hin) and motA mutations into the SL1344 background from the LT2 strains (Table 1) was carried out using standard transduction protocols from strains used and verified in previous studies (Table 1).

\section{Antibodies and purified proteins}

Abbreviations and/or Uniprot accession codes are in brackets. Sources, details and use of antibodies and stains are described in Table S3. Rabbit skeletal muscle $\alpha \beta$-actin (ACTB, P29751), human platelet $\beta \gamma$-actin (ACTB, P60709), recombinant human cofilin-1 (CFL1 P23528) and arp2/3 complex (ARPC4 Q148J6) from bovine brain were all purchased from Cytoskeleton Inc. Recombinant human galectin-4 (GAL4 P56470) and gelsolin (GSN Q3SX14) from bovine plasma were purchased from R\&D Systems and Sigma respectively.

Flagella were sheared from mutants $\mathrm{TUVfliC}_{\mathrm{HFF}}(\mathrm{H} 7, \mathrm{Q7DBI0}), \mathrm{TUVfliC}_{\mathrm{HGF}}$ (H6, B7USU2), TUVfliC::pEW5 (H48, P04949), SL1344 fljB $_{P 2}$ (phase-1, P1, FliC E1WGJ5) and SL1344 fliC $_{P 1}$ (phase-2, P2, FljB E1WA22), using an adapted protocol (56). TUV93-0 derivatives were cultured at $30^{\circ} \mathrm{C}$ and SL 1344 derivatives at $37^{\circ} \mathrm{C}$. Briefly, strains were cultured on $0.3 \%$ (w/v) LB agar for $24 \mathrm{~h}$. LB was inoculated with $10 \mu \mathrm{l}$ agar plugs from the leading edge of the motility halo and incubated at $200 \mathrm{rpm}$ for $16 \mathrm{~h}$. For purification of $\mathrm{H} 48$ flagella, TUVfliC:::pEW5 was grown in the presence of ampicillin at all times. TUVfliC::pEW5 was further sub-cultured in LB in the same conditions to $\mathrm{OD}_{600} 0.6$, at which point $1 \mathrm{mM} \mathrm{IPTG}$ was added and cultures were then grown to $\mathrm{OD}_{600} 1-1.5$. All cultures were centrifuged at $4,100 \times g$ at $4^{\circ} \mathrm{C}$ for $30 \mathrm{~min}$ and pellets were re-suspended $1: 10$ initial culture volume with cold Dulbecco $\mathrm{A}$ phosphate-buffered saline (PBS). These were then sheared for 2 min on ice with at maximum speed 
with an IKA T-10 homogeniser (Ultra-Turrax). Two to five rounds of centrifugation at $4,100 \times g$ at $4^{\circ} \mathrm{C}$ for $15 \mathrm{~min}$, then centrifugation once at $16,000 \times g$ at $4^{\circ} \mathrm{C}$ for $10 \mathrm{~min}$ were undertaken to obtain bacteriafree supernatants. These were centrifuged at $145,000 \times g 4^{\circ} \mathrm{C}$ for $1.5 \mathrm{~h}$ and re-suspended in PBS (or $50 \mathrm{mM}$ Tris- $\mathrm{HCl} \mathrm{pH} 7.5$ for actin polymerisation assays) at 1:500 of initial culture volumes. Protein concentration and purity was assessed using BCA, then confirmed by coomassie staining (Imperial protein stain, Thermo Fischer) and densitometry after SDS-PAGE.

Sheared flagella were monomerised according to the protocol published by Smith et al. (57). Flagella preparations were incubated at $70^{\circ} \mathrm{C}$ for 15 min then filtered by centrifugation at $5000 \times g$ at $4^{\circ} \mathrm{C}$ for 30 min using $100 \mathrm{kDa} 4 \mathrm{ml}$ filter units (Millipore). Filtrates were confirmed by size-exclusion HPLC to be exclusively monomeric.

\section{Tissue culture}

All cells were maintained at $37^{\circ} \mathrm{C}$, in $5 \% \mathrm{CO}_{2}$ and $80 \%$ humidity. The embryonic bovine lung epithelial (EBL, laboratory stocks), murine fibroblast (3T3, laboratory stocks) and HEK293 (laboratory stocks) cell lines were maintained in Dulbecco's minimal essential medium (DMEM, Sigma) supplemented with $10 \%(\mathrm{v} / \mathrm{v})$ foetal bovine serum (FBS, Sigma), $1 \mathrm{U}$ of penicillin (Invitrogen), $1 \mathrm{\mu g} / \mathrm{ml}$ of streptomycin (Invitrogen) and $2 \mathrm{mM} \mathrm{L-glutamine} \mathrm{(Invitrogen)} \mathrm{unless} \mathrm{otherwise} \mathrm{stated.} \mathrm{The} \mathrm{porcine} \mathrm{intestinal} \mathrm{epithelial}$ cell line IPEC-J2 was maintained as described by Schierack et al. (58), in HAMS/F-12 1:1 with 5\% FBS, $1 \mathrm{U}$ of penicillin and $1 \mu \mathrm{g} / \mathrm{ml}$ of streptomycin. Prior to bacterial infection, cultured cells were washed in MEM-HEPES and incubated at $37^{\circ} \mathrm{C}, 5 \% \mathrm{CO} 2,80 \%$ humidity for $1-2 \mathrm{~h}$. All bacterial infections were incubated in these conditions for the time specified unless otherwise stated.

\section{Primary cell culture}

Bovine rectal and porcine colonic epithelia were isolated from abattoir-derived tissue as described previously (59). The intestinal tissues were collected from material discarded as part of the normal work of the abattoir; while no licence was required for this, the relevant permissions were obtained from the West Lothian abattoir. The mucosal scrapings from bovine terminal rectal or porcine colonic tissue from a local abattoir were digested in DMEM [1\% (v/v) fetal calf serum (FCS), $100 \mathrm{U} / \mathrm{ml}$ penicillin, $30 \mu \mathrm{g} / \mathrm{ml}$ streptomycin, $25 \mu \mathrm{g} / \mathrm{ml}$ gentamicin] containing $75 \mathrm{U} / \mathrm{ml}$ collagenase and $20 \mu \mathrm{g} / \mathrm{ml}$ dispase (Roche) with gentle shaking at $37^{\circ} \mathrm{C}$ until isolated crypts could be observed microscopically. Crypt enrichment from undigested, contaminating gut microflora and single cells including fibroblasts, was performed using a series of differential centrifugation steps with DMEM containing $2 \%(w / v)$ sorbitol. Approximately 500 700 crypts were seeded per well on to collagen (Nutacon for bovine cultures, Porcogen for porcine cultures) coated plates. The bovine cells were grown for 5 days before use, and the porcine cells were 
grown to a stage of confluence (approximately $3 \times 10^{5}$ cells per well, typically at $10-14$ days following initial primary epithelial cell culture).

\section{Confocal microscopy}

Unless otherwise stated, all samples for confocal microscopy outlined below were washed three times in PBS, fixed for $>20 \mathrm{~min}$ RT in $4 \%$ (w/v) paraformaldehyde then permeabilised for $<1$ min with $0.1 \%$ $(\mathrm{v} / \mathrm{v})$ Triton X-100 prior to immediate washing as above and staining as below. All stains and antibodies were diluted in PBS. Where stained, cell nuclei were stained with DAPI (Table S3), and slides or coverslips were mounted with ProLong Gold (Invitrogen) unless otherwise stated. Image data was acquired with a Zeiss Plan Apochromat 1.4 NA x63 oil immersion lens and a multi-track (sequential scan) experimental set up on a Zeiss LSM510, using Axiovision software, unless otherwise stated.

For examination of $\mathrm{H} 7$ flagella interactions with actin, primary bovine rectal epithelial and $\mathrm{EBL}$ cells were used. For primary epithelial interactions, bovine crypts isolated from rectal epithelia were seeded onto collagen-coated 4-well Thermanox chamber slides as described (see primary cell culture section). Infection was for $1 \mathrm{~h}$ with $1 \times 10^{7} \mathrm{E}$. coli O157:H7 TUV93-0 grown at $28^{\circ} \mathrm{C} 200 \mathrm{rpm}$, sub-cultured to $\mathrm{OD}_{600}$ 0.3-0.4 and re-suspended in MEM-HEPES. These were then fixed, permeabilised and stained as described above, except that primary antibodies were labelled with FITC-conjugated a-rabbit IgG (Sigma). F-actin was then stained with Texas Red-conjugated phalloidin diluted 1:250, after which cell nuclei were stained with DAPI diluted 1:1000.

Where EBL cells were used, they were seeded onto glass coverslips $24 \mathrm{~h}$ prior to infection with exponential-phase E. coli O157:H7 TUV93-0. TUV93-0 was grown in 0.3\% (w/v) LB agar, sub-cultured into LB broth at $30^{\circ} \mathrm{C}$ for $16 \mathrm{~h} 200 \mathrm{rpm}$, then sub-cultured 1:100 in MEM-HEPES supplemented with $250 \mathrm{nM} \mathrm{Fe}^{2+}$ and $0.2 \%(\mathrm{w} / \mathrm{v})$ glucose at $37^{\circ} \mathrm{C}$ to an $\mathrm{OD}_{600} 0.3$. EBL cells were infected with TUV93-0 at an $\mathrm{MOI}$ of 20 for $3 \mathrm{~h}$. Samples were treated with $\alpha-\mathrm{H} 7$ rabbit $\lg$ diluted 1:100, then $\alpha-0157$ mouse IgG diluted 1:1000, followed by a co-incubation of AlexaFluor ${ }_{568}$-conjugated $\alpha$-rabbit $\operatorname{lgG}$ and AlexaFluor $_{568} \alpha$-mouse IgG both diluted 1:1000. F-actin was stained with FITC-conjugated phalloidin (Molecular Probes) diluted 1:100 for $2 \mathrm{~h}$. The cell nuclei were stained with DAPI diluted 1:5000.

For investigation of $S$. Typhimurium flagella interactions with host epithelia, confluent IPEC-J2 monolayers on glass coverslips were washed three times with MEM-HEPES immediately prior to infection with S. Typhimurium SL1344. Bacterial cultures were incubated in LB with $300 \mathrm{mM} \mathrm{NaCl}$ at $37^{\circ} \mathrm{C} 200 \mathrm{rpm}$ for $16 \mathrm{~h}$, then diluted to an $\mathrm{OD}_{600} 0.3 \mathrm{in} \mathrm{MEM-HEPES}$. IPEC-J2 cells were infected at an $\mathrm{MOI}$ of 20, for $20 \mathrm{~min}$. Samples were fixed with $2 \%(\mathrm{w} / \mathrm{v})$ PFA for $20 \mathrm{~min}$ then permeabilised with $0.2 \%$ $(\mathrm{v} / \mathrm{v})$ triton X-100 for $5 \mathrm{~min}$. Samples were treated with P1 or P2 specific rabbit IgG (a-Hi diluted 1:100 and $\mathrm{\alpha}-\mathrm{H} 2$ diluted 1:500 respectively) then $\alpha-\mathrm{O} 4$ rabbit $\lg$ diluted 1:500. This was then labelled with 
FITC-conjugated $\alpha$-rabbit IgG diluted 1:1000. F-actin was stained with Texas Red-conjugated phalloidin diluted 1:500 and slides were mounted in VectorShield (Vector Labs). Membrane staining of $S$. Typhimurium infected cells was undertaken in the same way, except that cells were infected for $10 \mathrm{~min}$ before fixation, and prior to permeabilisation, membranes were stained with Texas Red-conjugated wheat-germ agglutinin diluted 1:1000 for $2 \mathrm{~h}$ (32). Additionally, instead of Texas Red-conjugated phalloidin, F-actin was stained with AlexaFluor 647 -conjugated phalloidin.

For investigation of $\mathrm{H} 7$ flagella interactions with host cell membranes, HEK293 cells were transfected with a CRD-STREX-GFP construct that leads to fluorescent staining on the inner side of the plasma

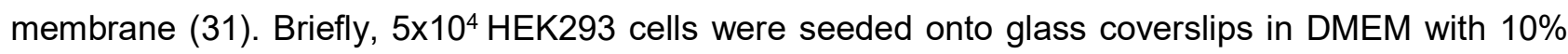
(v/v) FBS, $100 \mathrm{U} / \mathrm{ml}$ penicillin and $30 \mu \mathrm{g} / \mathrm{ml}$ streptomycin, and cultured to $40-70 \%$ confluence. $150 \mathrm{ng}$ of CRD-STREX-GFP plasmid was diluted in proprietary EC buffer (Qiagen) and enhancer was added to it at 1:125 ( $\mu \mathrm{l} / \mathrm{ng} \mathrm{DNA}$ ) and incubated for $5 \mathrm{~min}$ at RT. Effectene (Qiagen) was added in a 3:1 ratio to the enhancer and incubated for $10 \mathrm{~min}$ at RT. HEK293 cells were washed with PBS and fresh maintenance medium added. The DNA-Effectene mixture was diluted 1:5 in maintenance medium and added to cells 1:2. Protein expression was determined $24 \mathrm{~h}$ post transfection using GFP expression as a read-out. These cells were infected with E. coli 0157:H7 TUV93-0 for 90 min. Fixed then permeabilised samples were labelled with $\alpha-\mathrm{H} 7$ rabbit IgG then $\alpha-\mathrm{O} 157$ rabbit IgG (Table S3) diluted $1: 1000$ and $1: 100$ respectively. Primary antibodies were labelled with AlexaFluor ${ }_{568}$-conjugated $\alpha$-rabbit IgG diluted 1:1000. Volumetric 3D reconstructions of de-convolved images were undertaken using Volocity Visualisation software version 6.3

For all above confocal microscopy, image data was acquired at optimal z-slice sampling rates as determined by Zeiss software, with a 1024 x 1024 pixel image size. Image data was de-convolved using Huygens software (Scientific Volume Imaging, Netherlands). De-convolved models of image data were analysed and re-slices of z-stacks, montages and projection views were created using NIH ImageJ software, with final figures assembled in Adobe Photoshop CS5 and CS6. Co-incidence analysis was undertaken using the 24/10/2004 version of an open-source co-localisation plug-in downloadable from http://rsbweb.nih.gov/ij/plugins/colocalisation.html. Threshold values were set based on z-stack histograms to determine the Gaussian curve of background readings for each channel, and coincidence was output at a display value of 150 . Display values were designated co-incident, not colocalised, as total co-localisation was $<50 \%$.

For pre-/post-permeabilisation labelling, collagen (rat tail type 1, Sigma)-coated coverslips were coated in $35 \%(\mathrm{v} / \mathrm{v})$ ethanol for $4 \mathrm{~h}$ at $37^{\circ} \mathrm{C}$, washed in PBS then media, then seeded with IPEC-J2 cells for Salmonella infection and EBL cells for E. coli O157: $\mathrm{H} 7$ infection $24 \mathrm{~h}$ prior to infection. Cells at $50-80 \%$ 
confluence were washed with PBS, then incubated with MEM-HEPES for $1-2 \mathrm{~h}$ prior to infection with $1 \times 10^{7}$ cells of mid-exponential phase S. Typhimurium SL1344::pAJR145 (constitutively expressing eGFP) for $20 \mathrm{~min}$, or E. coli O157:H7 TUV93-0::pAJR145 (constitutively expressing eGFP) for $1 \mathrm{~h}$ respectively. Once infections had taken place, cells were fixed in $4 \%$ (v/v) PFA in PBS for 20 min $\mathrm{RT}^{\circ} \mathrm{C}$ and blocked with $3 \%(\mathrm{w} / \mathrm{v}) \mathrm{BSA}$ (PBS). All incubations were $1 \mathrm{~h}$, static, in the dark and at $\mathrm{RT}^{\circ} \mathrm{C}$. All washes and reagents were diluted in PBS alone, and washed 3 times with PBS between steps. Flagella were labelled 1:500 with $\alpha-\mathrm{P} 1+\mathrm{P} 2$ and $\alpha-\mathrm{H} 7$ polyclonal rabbit IgG (Table S3) for SL1344 and TUV93-0 infections respectively, then labelled 1:1000 with TRITC conjugated $\alpha$-rabbit IgG, before washing and permeabilisation with $0.1 \%(\mathrm{v} / \mathrm{v}) \mathrm{TX} 100$ for $30 \mathrm{~s}$. Flagella labelling was then repeated as above, but with FITC-conjugated a-rabbit IgG, then stained with Alexa-Fluor647 conjugated phalloidin (Invitrogen, 1:125 for $20 \mathrm{~min}$ ). Coverslips were mounted and images acquired using a Leica HCX Plan Apochromat 1.4 NA x100 oil immersion lens in a multi-track (sequential scan) experimental set up on a Leica SP5II confocal laser scanning microscope with Leica Application Suite X software.

\section{Correlative transmission electron tomography}

IPEC-J2 cells were seeded in rat-tail type I collagen(Sigma)-coated glass-bottomed 35mm $\mu$-Dishes etched with 4 reference grids (IBIDI) 24h before infection with S. Typhimurium SL1344:: pAJR145 (constitutively expressing eGFP) in the conditions stated for pre- and post-permeabilisation labelling experiments. After 20 min infection in the above conditions, cells were washed three times in PBS and fixed in 4\% (w/v) PFA. Cells were labelled 1:500 with a-FliC rabbit polyclonal IgG, then 1:1000 with FITC-conjugated a-rabbit IgG (Table S3). Dishes were not mounted but instead imaged in PBS using a Leica SP5II confocal laser scanning microscope to determine locations of cell-associated flagellated bacteria on the 4 reference grids.

Cells were fixed and embedded in preparation for electron tomography as follows. All wash steps and treatments were diluted in $\mathrm{ddH}_{2} \mathrm{O}$, unless otherwise stated. Fixation was undertaken in $2.5 \%(\mathrm{w} / \mathrm{v})$ glutaraldehyde (100mM sodium cacolydate $\mathrm{pH}$ 7.2) for $20 \mathrm{~min}$, then washed three times before postfixing with $1 \%(\mathrm{w} / \mathrm{v})$ osmium tetroxide for $20 \mathrm{~min}$. After a further three washes, cells were then stained with $3 \%(w / v)$ uranyl acetate for $20 \mathrm{~min}$ and washed three more times. Cells were then dehydrated with graded ethanol washes for $5 \mathrm{~min}$ each at 70\%, 80\%, 90\%, 96\%, 100\% (v/v) before adding 1:1 epon epoxy resin for $1 \mathrm{~h} 30 \mathrm{~min}$, rocking, to embed. Embedded samples were then baked at $200^{\circ} \mathrm{C}$ for $5 \mathrm{~d}$ before removal from glass dishes with snap-freeze/thawing. The reference grids on the remaining resin were then mounted onto stubs, trimmed to areas of interest determined by confocal microscopy (see also Olmos et al., (60)), and cut into $300 \mathrm{~nm}$ thick sections using a Leica EM UC7 with an IC80HD camera. Serial sections of areas of interest were placed onto film-coated copper slot grids (Agar 
Scientific) and further stained with 3\% (w/v) uranyl acetate for 20 min to enhance contrast before imaging. Washed grids were labelled with $15 \mathrm{~nm}$ gold particles both to the top and bottom of sections for 5 min then blotted dry.

Samples were mapped to determine the location of flagellated and cell-associated bacteria using a FEI $120 \mathrm{kV}$ BioTwin Spirit Transmission Electron microscope. Then TEM tilt series' (between $-60^{\circ}$ to +60 in $1.5^{\circ}$ increments) were acquired using a FEI $200 \mathrm{kV}$ Twin Lens Scanning Transmission Electron microscope and Xplore3D software (FEI). The tilt series' were reconstructed into electron tomograms using the standard workflow of IMOD and 3dMOD software packages (Boulder Laboratory for 3-D EM of cells, University of Colorado, USA), then analysed and presented using Amira 6.0.0, where an anisotropic diffusion filter was applied to the data, and FIJI software.

\section{Immuno-gold staining and scanning-electron microscopy}

The ultra-structural details of flagella interaction with specified epithelial cell types were visualised using Hitachi 4700 Field Emission Scanning Electron microscope. The specimens were fixed in 3\% gluteraldehyde in $100 \mathrm{mM}$ sodium cacodylate buffer $(\mathrm{pH} 7.4)$ and processed without permeabilisation for SEM as described previously (59). Immuno-gold labelling was visualised by detecting backscattered electrons; overlays of back scattering and secondary electrons were false-coloured in Adobe Photoshop CS4 for contrast.

\section{Haemolysis assays}

All bacterial cultures were inoculated with agar plugs from the leading edge of the motility halo of fresh motility plates of the strains indicated. These cultures were incubated statically in LB at RT for $16 \mathrm{~h}$. Cultures were adjusted to equal $\mathrm{OD}_{600}$ before addition to a $\mathrm{V}$-bottomed 96 well plate $1: 1$ (50 $\mu$ l each) with $50 \%(\mathrm{v} / \mathrm{v})$ washed sheep red blood cells (RBCs, Oxoid) in PBS. The bacteria were driven into contact with the RBCs by centrifugation at $2000 \times g$ for 5 min RT, then gently mixed by pipetting. Plates were incubated $37^{\circ} \mathrm{C} 2 \mathrm{~h}$. Samples were diluted $1: 1.5$ with $150 \mu$ PBS then gently mixed by pipetting. Plates were then centrifuged $2000 \times g$ for $10 \mathrm{~min}$ RT to pellet RBCs. The $\mathrm{A}_{405}$ of $100 \mu \mathrm{l}$ of supernatants were then measured as a read-out of total haem release. Independent replicates were undertaken 3-5 times, with technical replicates of 3-4. The mean level of haem release caused by incubation with LB alone was subtracted and data were normalised as $\%$ of wild-type haem release. After tests for equal variance were performed on raw data for each strain set in Minitab 17, homoscedastic 2-tailed T-tests were performed on the raw data, between mutant and wild-type strains.

\section{Preparation of cell lysates}

Bovine primary rectal epithelial cells were harvested by washing twice in PBS followed by incubation with TripLE Express (Gibco) at $37^{\circ} \mathrm{C}, 5 \% \mathrm{CO}_{2}, 80 \%$ humidity for $10 \mathrm{~min}$. An equal volume of PBS was 
added and then cells were scraped off, collected and centrifuged at $300 \times g$ for 2 min at RT. Cells were washed twice by re-suspending cell pellets and centrifuging in PBS or Hank's Balanced Salt Solution (HBSS). The cell pellet was re-suspended in PBS or HBSS, subjected to 5 cycles of snap-freezing in ethanol and dry-ice and thawing at RT, and clarified by centrifugation at $18,000 \times g$ for 10 min at $4^{\circ} \mathrm{C}$.

\section{Western and far-Western blotting}

$80 \mu \mathrm{g}$ of primary epithelial cell lysates or $1 \mu \mathrm{g}$ purified receptor candidates separated in SDS-PAGE gels were Western-blotted onto nitrocellulose (Amersham, GE Healthcare) with Schaeffer-Nielsen buffer (48mM Tris, 39mM glycine, 20\% (v/v) methanol, 0.04\% (v/v) SDS, pH 9.2), at 15V for 30-60 min. Blots were blocked in Carbofree (Vector Labs) or $0.1 \%$ (v/v) Tween 20 (Sigma) in PBS (PBST) with $5 \%$ (w/v) skimmed milk powder (Sigma, Marvel), at RT for $2 \mathrm{~h}$ or $4^{\circ} \mathrm{C}$ for $16 \mathrm{~h}$. Blots were washed three times between all subsequent steps in PBST alone for $15 \mathrm{~min}$ at RT, with rocking. For both Western and far-Western blots, antibodies were diluted in 1\% (w/v) skimmed milk powder in PBST and incubated with blots for $1 \mathrm{~h}$, rocking at RT.

Prior to antibody labelling, far-Western blots were first probed with $1 \mu \mathrm{g} / \mathrm{ml} \mathrm{H7}$ flagella in PBS for $3 \mathrm{~h}$, rocking at $\mathrm{RT}$. $\mathrm{H} 7$ flagella were then treated with $\alpha-\mathrm{H} 7$ rabbit $\lg \mathrm{G}$ diluted $1: 1000$, and this was labelled with horseradish peroxidase (HRP)-conjugated $\alpha$-rabbit IgG diluted 1:1000. Western blots of cell lysates were probed with $\alpha$-cofilin-1 mouse IgG diluted 1:500 or a-galectin-4 goat IgG diluted 1:1000, then a 1:1000 dilution of HRP-conjugated a-mouse or goat IgG respectively. Blots were then developed using Pico-West SuperSignal ECL reagents (Thermo Fischer) in a G:box (Syngene), and captured using GeneSnap (Syngene).

\section{Pull-down assays}

Cyanogen bromide $(\mathrm{CnBr})$ activated sepharose 4B lyophilised beads (GE Healthcare) were used according to manufacturer's instructions. $50 \mu \mathrm{g}$ of $\mathrm{H} 7$ flagella was added 2:1 to $\mathrm{CnBr}$ beads for $16 \mathrm{~h}$ at $4^{\circ} \mathrm{C}$, rocking, in coupling buffer $\left(100 \mathrm{mM} \mathrm{NaHCO}_{3} \mathrm{pH}^{2} .3\right.$ containing $\left.500 \mathrm{mM} \mathrm{NaCl}\right)$. Excess $\mathrm{H} 7$ flagella were washed off beads by five cycles of centrifugation at $18,000 \times g$ for $30 \mathrm{~s}$ then re-suspension of beads in equal volumes of coupling buffer. Following one additional centrifugation as above, beads were re-suspended in blocking buffer (100 mM Tris- $\mathrm{HCl}, 500 \mathrm{mM} \mathrm{NaCl}, \mathrm{pH} 8.0)$ and incubated for $2 \mathrm{~h}$ static at $\mathrm{RT}$. $\mathrm{CnBr}$ beads were then washed ten times by centrifugation as above, with alternate cycles of suspension in coupling buffer or wash buffer (100 mM acetic acid, $100 \mathrm{mM}$ sodium acetate, $500 \mathrm{mM}$ $\mathrm{NaCl}, \mathrm{pH}$ 4.0). On the final centrifugation, beads were suspended in $180 \mu \mathrm{g} \mathrm{BTRE}$ freeze-thawed cell lysate in HBSS and incubated for $16 \mathrm{~h}$ at $4^{\circ} \mathrm{C}$, rocking.

$\mathrm{CnBr}$ beads were centrifuged at $18,000 \times \mathrm{g}$ for $30 \mathrm{~s}$ then washed by three cycles of centrifugation as above and re-suspension in $0.1 \%(\mathrm{v} / \mathrm{v})$ PBST. Beads were centrifuged as above and eluted by 
incubation in $2 x$ SDS-PAGE sample buffer (Sigma) for $5 \mathrm{~min}$ at $100^{\circ} \mathrm{C}$ and centrifuged as above. Eluted proteins were then analysed by $12 \%$ SDS-PAGE and Imperial protein staining (Thermo Fischer). Bands visible only in the presence of $\mathrm{H} 7$ flagella-coated $\mathrm{CnBr}$ beads were considered likely ligand candidates and equivalent cell lysate bands were excised and identified by mass spectrometry.

\section{Mass spectrometry}

Mass-spectrometry, tandem mass-spectrometry and peptide mass fingerprinting were undertaken by Kevin McLean the Moredun Research Institute Proteomics Facility, UK. Protein bands from Imperial protein stained SDS-PAGE gels were excised and delivered to the proteomics facility. Here they were trypsinised, enriched, cleaned-up and matrix assisted laser desorption ionisation time of flight (MALDITOF MS/MS) was performed on a Bruker Ultraflexll according to their established protocols. Spectra were then input into MASCOT peptide mass fingerprinting software (Matrix Science) as monoisotopic $1+(\mathrm{m} / \mathrm{z})$ ratios using a $\pm 50 \mathrm{ppm}$ tolerance, to generate protein identities.

Accurate MW determination of $\mathrm{H} 6, \mathrm{H} 7, \mathrm{H} 48, \mathrm{P} 1$ and $\mathrm{P} 2$ was undertaken with online HPLC-MS in the facilities of Proteomics and Metabolomics at The Roslin Institute, UK. Samples of sheared flagella were diluted to $\sim 1 \mathrm{pmole} / \mu \mathrm{l}$ in $0.1 \%(\mathrm{v} / \mathrm{v})$ formic acid and $\sim 20$ pmole was applied to a microbore HPLC column (Dionex Acclaim C18, $4.6 \mathrm{~mm}$ i.d., 150mm length, $5 \mu \mathrm{m}$ beads, 120 Å pore size) pre-equilibrated with $0.1 \%(\mathrm{v} / \mathrm{v})$ formic acid by use of a Ultimate HPLC system (Dionex). Bound components were eluted with a gradient of $0.1 \%(\mathrm{v} / \mathrm{v})$ formic acid in acetonitrile into the electrospray source of an amaZon ETD ion trap mass spectrometer (Bruker Daltonics, Germany). The mass spectrometer acquired full scan mass spectra with final spectra being an average of 8 trap fills of a maximum averaging time of $200 \mathrm{~ms}$. Signals corresponding to intact flagellin were summed, the raw data was smoothed and background subtracted and then de-convoluted by use of the Bruker proprietary algorithm.

\section{Enzyme-linked immuno-sorbent assays (ELISA)}

$1 \mu \mathrm{g}$ per well of $95 \%$ pure human platelet $\beta \gamma$-actin, recombinant human galectin-4 and recombinant human cofilin-1 were adsorbed to 96 -well Nunc Maxisorb plates in $100 \mathrm{mM}$ sodium bicarbonate pH 9.6 for $16 \mathrm{~h}$ at $4^{\circ} \mathrm{C}$. Wells were blocked using Carbo-free (VectorLabs) for $2 \mathrm{~h}$, at RT, before washing. All wash steps involved washing three times in PBST (0.1\% Tween 20$)$. Polymers and monomers of each flagella type (as verified by size exclusion chromatography), were diluted in PBS only at 1000, 500, 100 and $0 \mathrm{ng}$ per well, in specific wells for $3 \mathrm{~h}$, before washing. Antibodies were diluted in PBST and incubated in wells for $1 \mathrm{~h}$, before washing. $\mathrm{H} 6, \mathrm{H} 7, \mathrm{P} 1$ and $\mathrm{P} 2$ flagella specific rabbit $\lg \mathrm{G}$ ( $\mathrm{\alpha}-\mathrm{H} 6$ and $\alpha-$ H7 1:1000; $\alpha-H i$ 1:100; $\alpha-H 2$ 1:500 respectively, Table S3) followed by HRP-conjugated $\alpha$-rabbit IgG were used to label flagella-specific binding. 
Flagella binding was detected using Pico-West SuperSignal ECL reagents (Thermo Fischer) in a G:Box using GeneSnap (Syngene) at a fixed distance of $575 \mathrm{~mm}$. Densitometry on wells was performed in GeneTools (Syngene), using a fixed spot radius of 25. Data were normalised according to the formula: Relative binding $=100 \times\left[\left(\right.\right.$ Test- $\left.\left.\mathrm{C}^{-}\right) /\left(\bar{x} \mathrm{C}^{+}-\mathrm{C}^{-}\right)\right]$, where $\mathrm{C}^{-}=0 \mathrm{ng}$ flagella protein, $\mathrm{C}^{+}=$positive detection control. This normalisation takes into account background from antibodies and assay to assay variation. In addition to this, no primary antibody and no ligand coating qualitative controls were performed.

Statistical analysis was carried out in $\mathrm{R}$ on $\log _{10}$ data from four independent experiments. Data residuals were assessed for normality using a normality plot. As it was not biologically appropriate to statistically compare different flagella types or ligand types, separate linear mixed effects models of relative binding were used to assess the statistical significance of each flagella type binding to each ligand candidate (galectin-4, cofilin-1 and actin). Flagella concentration (1000, 500, $100 \mathrm{ng} /$ well) and polymerisation status (polymer and monomer) were fixed effects and experiment was a random effect. Pairwise comparisons of the interaction between polymerisation statuses for each flagella type in each model were then performed on the data. To correct for the large number of comparisons, an alpha level of $p<0.01$ was taken as significant.

\section{Actin polymerisation assays}

Actin polymerisation assays were carried out as described by Sitthidet et al. with minor modifications (61) and informed by Van Troys et al. (37). G-actin was prepared by re-suspending lyophilised pyreneconjugated rabbit skeletal muscle $\alpha \beta$-actin in G-buffer $\left(10 \mathrm{mM}\right.$ Tris- $\mathrm{HCl}, 200 \mu \mathrm{M} \mathrm{CaCl}_{2}, 200 \mu \mathrm{M} \mathrm{ATP}$, $1 \mathrm{mM}$ DTT, $\mathrm{pH}$ 7.5) for $1 \mathrm{~h}$ on ice, in the dark. This was then centrifuged at $100,000 \times \mathrm{g}$ for $2 \mathrm{~h}$ at $4^{\circ} \mathrm{C}$. The top $80 \%$ supernatant was kept on ice in the dark. Test proteins were re-suspended as purified or dialysed with U-tube concentrators (Novagen) into $50 \mathrm{mM}$ Tris- $\mathrm{HCl} \mathrm{pH} \mathrm{7.5.} \mathrm{Molar} \mathrm{concentrations} \mathrm{of} \mathrm{all}$ protein components were calculated using a Bradford assay with a BSA standard curve. Densitometry of coomassie-stained SDS-PAGE gels was used to adjust flagella values.

Assays were carried out in black opaque 96-well plates (Nunc). $1 \mu \mathrm{M}$ actin was added to wells with 50 $\mathrm{mM}$ Tris- $\mathrm{HCl} \mathrm{pH}$ 7.5. Cofilin-1 and serially diluted flagella preparations were then added, followed by polymerisation buffer (at a final concentration of $5 \mathrm{mM} \mathrm{KCl}, 0.2 \mathrm{mM} \mathrm{MgCl}_{2}$ and $0.1 \mathrm{mM} \mathrm{ATP}$ ). Samples were excited at $365 \mathrm{~nm}$, and emission data was measured at $407 \mathrm{~nm}$ for $1 \mathrm{~h}$, at $30 \mathrm{~s}$ intervals. A daily gain value was applied to all wells to normalise actin polymerisation capability and this was calculated using pyrene-actin fluorescence after $1 \mathrm{~h}$ polymerisation at RT as above.

Maximum velocity $\left(V_{\max }\right)$ of actin polymerisation was calculated with the formula $V_{\max }=\left(A_{2}-A_{1}\right) /\left(T_{2}-T_{1}\right)$, where $\mathrm{A}=$ absorbance at $407 \mathrm{~nm}$ and $\mathrm{T}=$ time. Differences due to addition of flagella were assessed for statistical significance using GLMs in Minitab 16.2.4. In these models, $V_{\max }$ was the response and 
replicate was a random factor. With flagella titration experiments, GLM analysis was carried out on data from 5 independent experiments; flagella type and concentration were fixed factors. Post-hoc Tukey pairwise comparisons of the interaction between flagella type and concentration were carried out. With flagella \pm cofilin-1 experiments, GLM analysis was carried out on data from three independent experiments; flagella type and cofilin-1 concentration were fixed factors. Post-hoc Tukey pairwise comparisons of the interaction between cofilin-1 concentration and flagella type were carried out as a very conservative estimate of differences based on the set of assumptions in a GLM statistical model. Therefore, if $p$-values are $<0.05$ they are very likely to be valid and so were taken as statistically significant.

\section{Size exclusion chromatography}

Samples were applied to an HPLC column (Sigma TSK G4000SWXL, $4.6 \mathrm{~mm}$ i.d., $300 \mathrm{~mm}$ length, 8 $\mu \mathrm{m}$ beads, $450 \AA$ pore size) pre-equilibrated with $100 \mathrm{mM}$ Tris- $\mathrm{HCl}, 200 \mathrm{mM} \mathrm{NaCl}, 1 \mathrm{mM}$ DTT, pH 8.0, by use of an Ultimate HPLC system (Dionex), measuring absorbance at $220 \mathrm{~nm}$. Columns were calibrated by the maximum peak of elution of individual molecular weight standards: Blue Dextran (2.5 $\mathrm{MDa}$ ) at $\sim 5 \mathrm{ml}$, BSA (66 kDa) at $\sim 10 \mathrm{ml}$ and Ribonuclease A (13.5 kDa) and ATP (0.5 Da) both at $\sim 12$ $\mathrm{ml}$.

For verification of flagellin polymerisation status, polymeric and monomeric $\mathrm{H} 6, \mathrm{H} 7, \mathrm{H} 48, \mathrm{P} 1$ and P2 flagellin purified into $50 \mathrm{mM}$ Tris- $\mathrm{HCl} \mathrm{pH} 7.5$ were applied neat to the column three times at $30 \mathrm{~min}$ intervals, with three blank runs in between flagella types. Data was analysed by establishing the lowest value of all runs as a baseline and calculating the area under curve (AUC) for each run, and looking at the ratio of filaments $(4.5-9 \mathrm{ml} \approx>2 \mathrm{MDa}-\sim 300 \mathrm{kDa})$ to monomers $(9-11.25 \mathrm{ml}<\sim 300 \mathrm{kDa})$ with the formula $A \cup C=\left[\left(A_{1}+A_{2}\right) / 2\right] \times\left(T_{2}-T_{1}\right)$, where $A=$ absorbance at $220 \mathrm{~nm}$ and $T=$ time $(\mathrm{ml})$.

\section{Acknowledgements}

We would like to thank Sutherland Maciver (Edinburgh) for advice on cofilin-1, Kevin Mclean at the Moredun Research Institute proteomics facility for peptide mass fingerprinting, Mike Shipston (Edinburgh) for supplying the STREX-GFP construct, and Phillip Aldridge (Newcastle), Roberto La Ragione (Surrey) and Mark Jepson (Bristol) for supplying reagents and strains, and the Centre for Integrative Physiology (University of Edinburgh) and Wolfson Bioimaging Facility (University of Bristol). We would also like to thank lan Thompson for his advice and support over the last decade. 


\section{References}

1. Yang Y, Sourjik V (2012) Opposite responses by different chemoreceptors set a tunable preference point in Escherichia coli pH taxis. Mol Microbiol. doi:10.1111/mmi.12070.

2. Berg HC, Anderson RA (1973) Bacteria swim by rotating their flagellar filaments. Nature. doi:10.1038/245380a0.

3. Chevance FF V, Hughes KT (2008) Coordinating assembly of a bacterial macromolecular machine. Nat Rev Microbiol 6(6):455-65.

4. Berg HC (2003) The rotary motor of bacterial flagella. Annu Rev Biochem 72:19-54.

5. Buttner D (2012) Protein export according to schedule: architecture, assembly, and regulation of type III secretion systems from plant- and animal-pathogenic bacteria. Microbiol Mol Biol Rev 76(2):262-310.

6. Diepold A, Armitage JP (2015) Type III secretion systems: the bacterial flagellum and the injectisome. Philos Trans R Soc Lond B Biol Sci 370(1679). doi:10.1098/rstb.2015.0020.

7. Vonderviszt F, Uedaira H, Kidokoro SI, Namba K (1990) Structural organization of flagellin. J Mol Biol. doi:10.1016/0022-2836(90)90149-G.

8. Zieg J, Silverman M, Hilmen M, Simon M (1977) Recombinational switch for gene expression. Science (80-). doi:10.1126/science.322276.

9. Yonekura K, Maki-Yonekura S, Namba K (2003) Complete atomic model of the bacterial flagellar filament by electron cryomicroscopy. Nature 424(6949):643-650.

10. Hayashi F, et al. (2001) The innate immune response to bacterial flagellin is mediated by Tolllike receptor 5. Nature 410(6832):1099-1103.

11. Zhao Y, et al. (2011) The NLRC4 inflammasome receptors for bacterial flagellin and type III secretion apparatus. Nature 477(7366):596-602.

12. Miao EA, Andersen-Nissen E, Warren SE, Aderem A (2007) TLR5 and Ipaf: Dual sensors of bacterial flagellin in the innate immune system. Semin Immunopathol 29(3):275-288.

13. Yoon S, et al. (2012) Structural basis of TLR5-flagellin recognition and signaling. Science 335(6070):859-864.

14. Belas R (2014) Biofilms, flagella, and mechanosensing of surfaces by bacteria. Trends 
Microbiol 22(9):517-527.

15. Song F, et al. (2017) How Bacteria Respond to Material Stiffness during Attachment: A Role of Escherichia coli Flagellar Motility. ACS Appl Mater Interfaces. doi:10.1021/acsami.7b04757.

16. Floyd M, et al. (2016) Swimming Motility Mediates the Formation of Neutrophil Extracellular Traps Induced by Flagellated Pseudomonas aeruginosa. PLoS Pathog. doi:10.1371/journal.ppat.1005987.

17. Pallen MJ, Matzke NJ (2006) From The Origin of Species to the origin of bacterial flagella. Nat Rev Microbiol 4(10):784-790.

18. Knutton S, Baldwin T, Williams PH, McNeish AS (1989) Actin accumulation at sites of bacterial adhesion to tissue culture cells: basis of a new diagnostic test for enteropathogenic and enterohemorrhagic Escherichia coli. Infect Immun 57(4):1290-1298.

19. Goosney DL, Celli J, Kenny B, Finlay BB (1999) Enteropathogenic Escherichia coli inhibits phagocytosis. Infect Immun 67(2):490-495.

20. Hayward RD, Leong JM, Koronakis V, Campellone KG (2006) Exploiting pathogenic Escherichia coli to model transmembrane receptor signalling. Nat Rev Microbiol 4(5):358-370.

21. Haraga A, Ohlson MB, Miller SI (2008) Salmonellae interplay with host cells. Nat Rev Microbiol 6(1):53-66.

22. Mahajan A, et al. (2009) An investigation of the expression and adhesin function of $\mathrm{H} 7 \mathrm{flagella}$ in the interaction of Escherichia coli O157: $\mathrm{H} 7$ with bovine intestinal epithelium. Cell Microbiol 11(1):121-137.

23. Dziva F, van Diemen PM, Stevens MP, Smith AJ, Wallis TS (2004) Identification of Escherichia coli $0157: H 7$ genes influencing colonization of the bovine gastrointestinal tract using signaturetagged mutagenesis. Microbiology 150(11):3631-3645.

24. Naylor SW, Gally DL, Christopher Low J (2005) Enterohaemorrhagic E. coli in veterinary medicine. Int J Med Microbiol 295(6-7):419-441.

25. Erdem AL, Avelino F, Xicohtencatl-Cortes J, Girón JA (2007) Host protein binding and adhesive properties of $\mathrm{H} 6$ and $\mathrm{H} 7$ flagella of attaching and effacing Escherichia coli. $J$ Bacteriol 189(20):7426-7435.

26. Rossez Y, et al. (2014) Flagella interact with ionic plant lipids to mediate adherence of 
pathogenic Escherichia coli to fresh produce plants. Environ Microbiol 16(7). doi:10.1111/14622920.12315.

27. Velge $\mathrm{P}$, et al. (2012) Multiplicity of Salmonella entry mechanisms, a new paradigm for Salmonella pathogenesis. Microbiologyopen 1(3):243-258.

28. Olsen JE, et al. (2013) The role of flagella and chemotaxis genes in host pathogen interaction of the host adapted Salmonella enterica serovar Dublin compared to the broad host range serovar S. Typhimurium. BMC Microbiol 13:67.

29. Agbor TA, McCormick BA (2011) Salmonella effectors: important players modulating host cell function during infection. Cell Microbiol 13(12):1858-1869.

30. Rossez Y, Wolfson EB, Holmes A, Gally DL, Holden NJ (2015) Bacterial Flagella: Twist and Stick, or Dodge across the Kingdoms. PLoS Pathog 11(1). doi:10.1371/journal.ppat.1004483.

31. Tian L, et al. (2008) Palmitoylation gates phosphorylation-dependent regulation of BK potassium channels. Proc Natl Acad Sci U S A 105(52):21006-21011.

32. Wright CS (1984) Structural comparison of the two distinct sugar binding sites in wheat germ agglutinin isolectin II. J Mol Biol 178(1):91-104.

33. Chattopadhyay S, Moldovan R, Yeung C, Wu XL (2006) Swimming efficiency of bacterium \&lt;em\&gt;Escherichia\&lt;/em\&gt;\&lt;em\&gt;coli\&lt;/em\&gt; Proc Natl Acad Sci 103(37):13712 LP - 13717.

34. Magariyama Y, Sugiyama S, Kudo S (2001) Bacterial swimming speed and rotation rate of bundled flagella. FEMS Microbiol Lett 199(1):125-129.

35. Parish CR, Wistar R, Ada GL (1969) Cleavage of bacterial flagellin with cyanogen bromide. Antigenic properties of the protein fragments. Biochem J 113(3):501-506.

36. Carlsson AE (2006) Stimulation of actin polymerization by filament severing. Biophys $J$ 90(2):413-422.

37. Van Troys M, et al. (2008) Ins and outs of ADF/cofilin activity and regulation. Eur J Cell Biol 87(8-9):649-667.

38. Crawford RW, Reeve KE, Gunn JS (2010) Flagellated but not hyperfimbriated Salmonella enterica serovar typhimurium attaches to and forms biofilms on cholesterol-coated surfaces. $J$ Bacteriol 192(12):2981-2990. 
39. Friedlander RS, Vogel N, Aizenberg J (2015) Role of Flagella in Adhesion of Escherichia coli to Abiotic Surfaces. Langmuir. doi:10.1021/acs.langmuir.5b00815.

40. Qi M, Gong X, Wu B, Zhang G (2017) Landing Dynamics of Swimming Bacteria on a Polymeric Surface: Effect of Surface Properties. Langmuir. doi:10.1021/acs.langmuir.7b00439.

41. Misselwitz B, et al. (2012) Near surface swimming of salmonella Typhimurium explains targetsite selection and cooperative invasion. PLoS Pathog. doi:10.1371/journal.ppat.1002810.

42. Friedlander RS, et al. (2013) Bacterial flagella explore microscale hummocks and hollows to increase adhesion. Proc Natl Acad Sci. doi:10.1073/pnas.1219662110.

43. Horstmann JA, et al. (2017) Flagellin phase-dependent swimming on epithelial cell surfaces contributes to productive Salmonella gut colonisation. Cell Microbiol. doi:10.1111/cmi.12739.

44. Bucior I, Pielage JF, Engel JN (2012) Pseudomonas aeruginosa pili and flagella mediate distinct binding and signaling events at the apical and basolateral surface of airway epithelium. PLoS Pathog 8(4):e1002616.

45. Lillehoj EP, Kim BT, Kim KC (2015) Identification of Pseudomonas aeruginosa flagellin as an adhesin for Muc1 mucin . Am J Physiol Cell Mol Physiol 282(4):L751-L756.

46. Kato K, et al. (2012) Membrane-tethered MUC1 mucin is phosphorylated by epidermal growth factor receptor in airway epithelial cells and associates with TLR5 to inhibit recruitment of MyD88. J Immunol 188(4):2014-2022.

47. Schmitt CK, et al. (2001) Absence of all components of the flagellar export and synthesis machinery differentially alters virulence of Salmonella enterica serovar Typhimurium in models of typhoid fever, survival in macrophages, tissue culture invasiveness, and calf enterocolitis. Infect Immun 69(9):5619-5625.

48. Mellmann A, et al. (2008) Analysis of collection of hemolytic uremic syndrome-associated enterohemorrhagic Escherichia coli. Emerg Infect Dis 14(8):1287-1290.

49. Giron JA, Torres AG, Freer E, Kaper JB (2002) The flagella of enteropathogenic Escherichia coli mediate adherence to epithelial cells. Mol Microbiol 44(2):361-379.

50. Eckhard U, et al. (2017) Discovery of a proteolytic flagellin family in diverse bacterial phyla that assembles enzymatically active flagella. Nat Commun 8(1):521.

51. Tilney LG, Portnoy DA (1989) Actin filaments and the growth, movement, and spread of the 
intracellular bacterial parasite, Listeria monocytogenes. J Cell Biol 109(4):1597 LP - 1608.

52. Gouin E, et al. (1999) A comparative study of the actin-based motilities of the pathogenic bacteria Listeria monocytogenes, Shigella flexneri and Rickettsia conorii. J Cell Sci 112 ( Pt 1:1697-1708.

53. Patel JC, Galán JE (2005) Manipulation of the host actin cytoskeleton by Salmonella--all in the name of entry. Curr Opin Microbiol 8(1):10-15.

54. Caron E, et al. (2006) Subversion of actin dynamics by EPEC and EHEC. Curr Opin Microbiol $9(1): 40-45$.

55. Blomfield IC, Vaughn V, Rest RF, Eisenstein BI (1991) Allelic exchange in Escherichia coli using the Bacillus subtilis sacB gene and a temperature-sensitive pSC101 replicon. Mol Microbiol 5(6):1447-1457.

56. Montie TC, Stover GB (1983) Isolation and characterization of flagellar preparations from Pseudomonas species. J Clin Microbiol 18(3):452-456.

57. Smith KD, et al. (2003) Toll-like receptor 5 recognizes a conserved site on flagellin required for protofilament formation and bacterial motility. Nat Immunol 4(12):1247-1253.

58. Schierack P, et al. (2006) Characterization of a porcine intestinal epithelial cell line for in vitro studies of microbial pathogenesis in swine. Histochem Cell Biol 125(3):293-305.

59. Mahajan A, et al. (2005) Phenotypic and functional characterisation of follicle-associated epithelium of rectal lymphoid tissue. Cell Tissue Res 321(3):365-374.

60. Olmos Y, Hodgson L, Mantell J, Verkade P, Carlton JG (2015) ESCRT-III controls nuclear envelope reformation. Nature 522(7555):236-239.

61. Sitthidet C, et al. (2011) Identification of motifs of Burkholderia pseudomallei BimA required for intracellular motility, actin binding, and actin polymerization. J Bacteriol 193(8):1901-1910.

62. Campellone KG, et al. (2007) Increased adherence and actin pedestal formation by damdeficient enterohaemorrhagic Escherichia coli O157:H7. Mol Microbiol 63(5):1468-1481.

63. Iguchi A, et al. (2009) Complete genome sequence and comparative genome analysis of enteropathogenic Escherichia coli O127:H6 strain E2348/69. J Bacteriol 191(1):347-54.

64. Blattner FR, et al. The Complete Genome Sequence of Escherichia coli K-12 Available at: www.sciencemag.org. 
65. Flockhart AF, et al. (2012) Identification of a novel prophage regulator in Escherichia coli controlling the expression of type III secretion. Mol Microbiol 83(1):208-223.

66. Arques JL, et al. (2009) Salmonella Induces Flagellin- and MyD88-Dependent Migration of Bacteria-Capturing Dendritic Cells Into the Gut Lumen. Gastroenterology. doi:10.1053/j.gastro.2009.04.010.

67. Richardson EJ, et al. (2011) Genome Sequences of \&lt;span class=\&quot;named-content genus-species\&quot; id=\&quot;named-content-1\&quot;\&gt;Salmonella enterica\&lt;/span\&gt; Serovar Typhimurium, Choleraesuis, Dublin, and Gallinarum Strains of Well- Defined Virulence in Food-Producing An. J Bacteriol 193(12):3162 LP - 3163.

68. Morgan E, et al. (2004) Identification of host-specific colonization factors of Salmonella enterica serovar Typhimurium. Mol Microbiol 54(4):994-1010.

69. Kwang J, Wilson R, Yang S, He Y (1996) Mapping of the H7-Serospecific Domain of Escherichia coli Flagellin.

70. Pettersen EF, et al. (2004) UCSF Chimera--a visualization system for exploratory research and analysis. J Comput Chem 25(13):1605-12.

71. Leffler H, Masiarz FR, Barondes SH (1989) Soluble lactose-binding vertebrate lectins: a growing family. Biochemistry 28(23):9222-9229.

72. Oda Y, et al. (1993) Soluble lactose-binding lectin from rat intestine with two different carbohydrate-binding domains in the same peptide chain. J Biol Chem 268(8):5929-5939.

73. Roe AJ, et al. (2004) Co-ordinate single-cell expression of LEE4- and LEE5-encoded proteins of Escherichia coli O157:H7. Mol Microbiol 54(2):337-352.

74. Merlin C, McAteer S, Masters M (2002) Tools for characterization of Escherichia coli genes of unknown function. J Bacteriol 184(16):4573-81.

75. Xu X, et al. (2012) Lysogeny with Shiga Toxin 2-Encoding Bacteriophages Represses Type III Secretion in Enterohemorrhagic Escherichia coli. PLoS Pathog 8(5):e1002672.

76. Paton AW, Paton JC (1998) Detection and characterization of shiga toxigenic escherichia coli by using multiplex PCR assays for stx1, stx2, eaeA, enterohemorrhagic E. coli hlyA, rfb(O111), and rfb(O157). J Clin Microbiol.

\section{Tables}


Table 1. Strains used or constructed in this study.

\begin{tabular}{|c|c|c|}
\hline Strain & Relevant features & Source \\
\hline TUV93-0 & E.coli 0157:H7; EDL933 (ATCC 700927) stx & $(62)$ \\
\hline TUVAfliC & TUV93-0 fliC::sacB::kan', aflagellate & $(26)$ \\
\hline TUVflic- & TUV93-0 fliC', aflagellate & $(26)$ \\
\hline TUVfliC $_{H 7 F}$ & TUV $\Delta$ fliC cis complement fliC ${ }_{H 7}$ from TUV93-0 & This study \\
\hline TUVfliC $_{\mathrm{H} 6 \mathrm{~F}}$ & TUV $\Delta$ fliC cis complement fli $C_{H 6}$ from E2348/69 & This study \\
\hline ZAP1574 & TUV93-0 $\Delta m o t A$ & This study \\
\hline ZAP1575 & TUV93-0 motA- & This study \\
\hline ZAP1576 & TUV93-0 motA-complemented & This study \\
\hline ZAP734 & E. coli O157:H7 NCTC 12900, Stx- & AHVLA \\
\hline E2348/69 & E.coli O127:H6; sequenced & $(63)$ \\
\hline MG1655 & E. coli $\mathrm{K} 12$; sequenced & $(64)$ \\
\hline TUV $\triangle L E E 1-2$ & 8.9 Kb deletion in LEE1-3, ETTA1 & $(65)$ \\
\hline SL1344 & S. Typhiumurium & $(66)$ \\
\hline $\mathrm{SL} 1344 \Delta f l j B_{P 2}$ & SL1344 $\Delta$ fljB by $\lambda$ red, expresses only P1 & $(66)$ \\
\hline $\mathrm{SL} 1344 \Delta$ fliC $_{P 1}$ & SL1344 $\Delta$ fliC by $\lambda$ red, expresses only P2 & $(66)$ \\
\hline SL1344 $\Delta f l i C_{P 1}$ & SL1344 $\Delta f l i C$ and $\Delta f l j B$ by $\lambda$ red, aflagellate & $(66)$ \\
\hline \multicolumn{3}{|l|}{$\Delta f l j B_{P 2}$} \\
\hline ZAP1566 & $\begin{array}{l}\text { S. Typhiumurium LT2 fliM5978-GFP } \\
\text { motAB::Tc }{ }^{R} \text {, non-motile }\end{array}$ & $\begin{array}{l}\text { P. Aldridge Lab, } \\
\text { Newcastle }\end{array}$ \\
\hline $\mathrm{SL} 1344 \triangle m o t A B$ & $\begin{array}{l}\text { SL1344 P22 transduced with ZAP1566, non- } \\
\text { motile }\end{array}$ & This study \\
\hline \multirow[t]{2}{*}{ Maskan } & S. Typhimurium & Stock from \\
\hline & & $\begin{array}{l}\text { Lohmann Animal } \\
\text { Health }\end{array}$ \\
\hline $4 / 74$ & S. Typhimurium & $(67)$ \\
\hline 4/74 $\mathrm{prgH}^{-}$ & $\operatorname{prgH}:$ : mini-Tn $5 \mathrm{Km} 2$ mutant of ST4/74 $\mathrm{Nal}^{\mathrm{R}}$ & $(68)$ \\
\hline
\end{tabular}




\section{Supplementary Information}

Figure S1. Confocal microscopy of intracellular interactions of $\mathrm{H7}$ flagella with host cells. Confocal z-slices of E. coli O157:H7 TUV93-0 flagella (green) interacting with actin (red). Nuclei staining is cyan. (A1) XY projection of TUV93-0 interacting with EBL cells, $3 \mathrm{~h}$ post infection. The micro-colony indicated with an arrow shows an $\mathrm{H} 7$ flagellum curling round $\mathrm{A} / \mathrm{E}$ lesions. The labelled inset marks the $X Z$ and $Y Z$ projections analysed in B1-B2. (B1-B2) Arrows point to specific regions within individual $X Z$ (B1) and $Y Z$ (B2) slices in which $\mathrm{H} 7$ flagellum is inside a region of actin staining. (C1) Top panel shows an $X Y$ projection of the whole field from which the images in Fig. 1A were taken. Middle panels show Fig. $1 A X Z$ and $Y Z$ projections, free of actin/flagellum co-incidence labelling. Lower panels show actin$\mathrm{H} 7$ flagellum co-incidence (yellow) across individual z-slices in $\mathrm{XZ}$ and $\mathrm{YZ}$ planes. Scale bars $=5 \mu \mathrm{m}$.

(Figure on next page) 
bioRxiv preprint doi: https://doi.org/10.1101/2020.02.12.945204; this version posted February 13, 2020. The copyright holder for this preprint (which was not certified by peer review) is the author/funder, who has granted bioRxiv a license to display the preprint in perpetuity. It is made available under aCC-BY-NC-ND 4.0 International license.
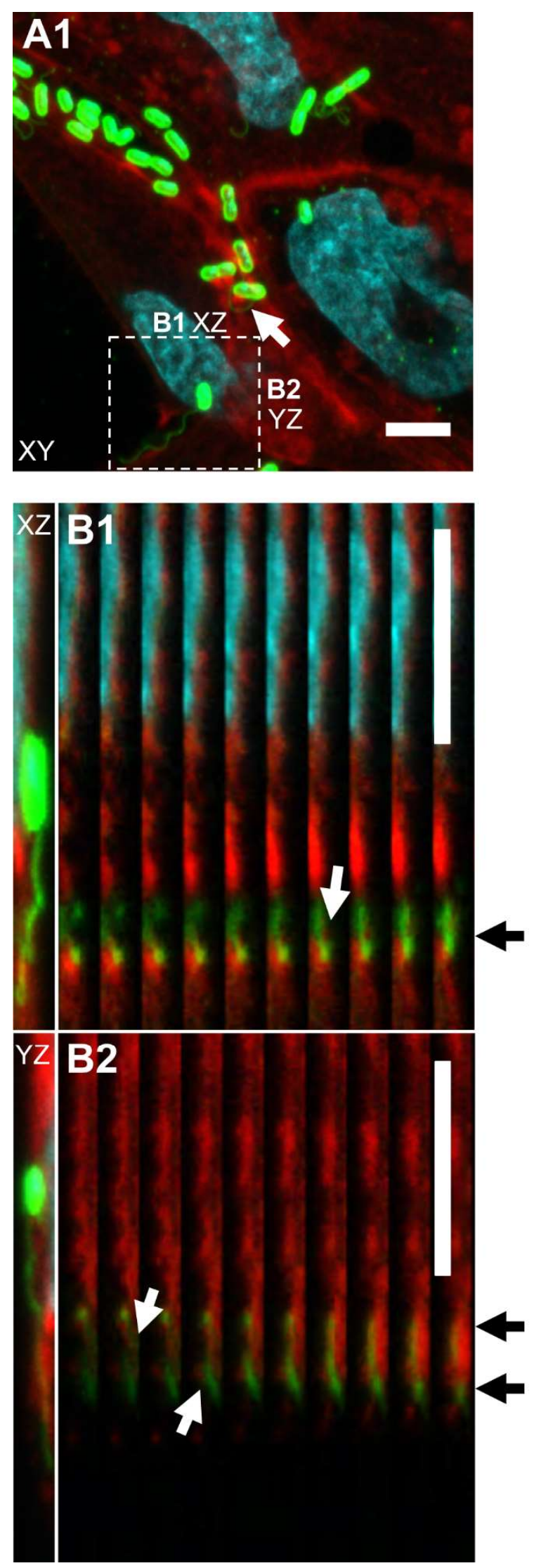
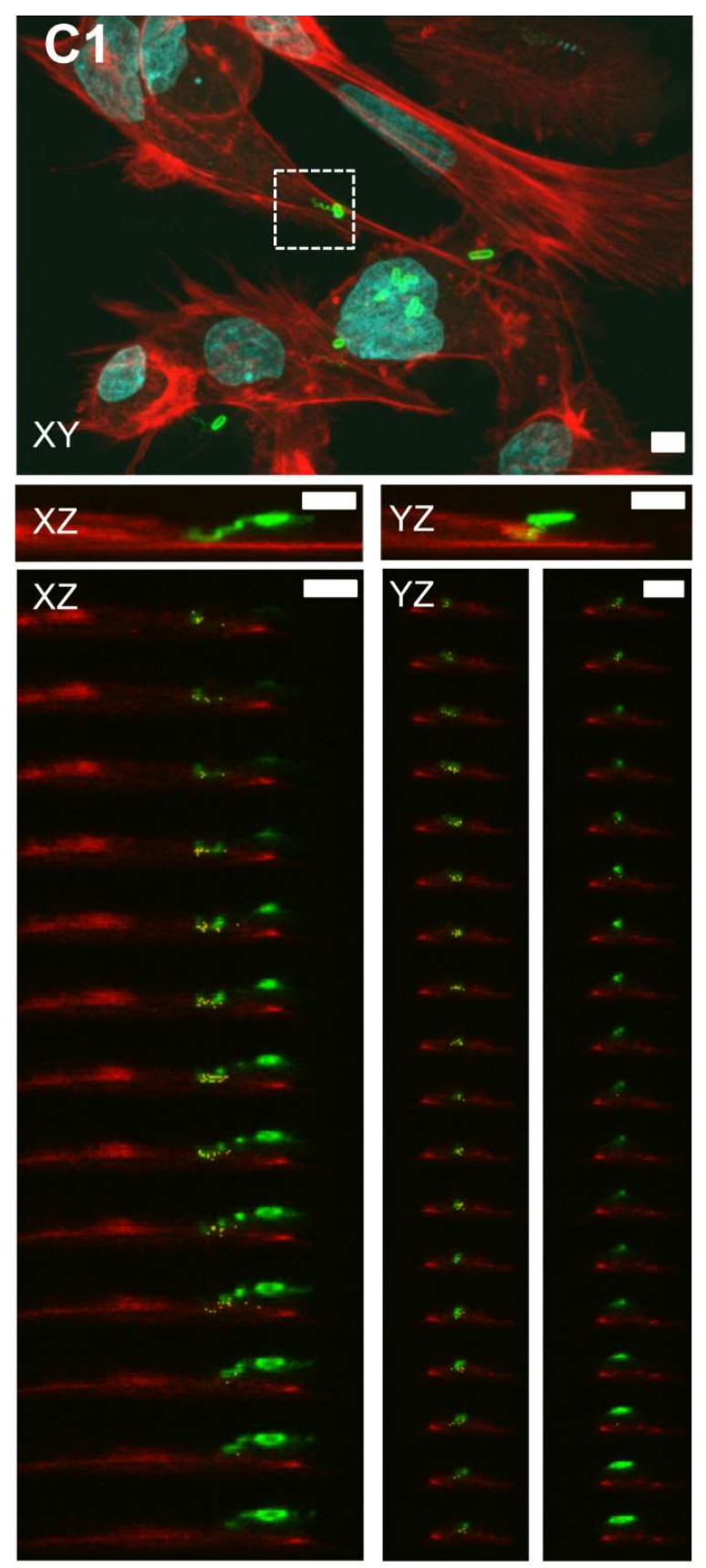

Page | 37 


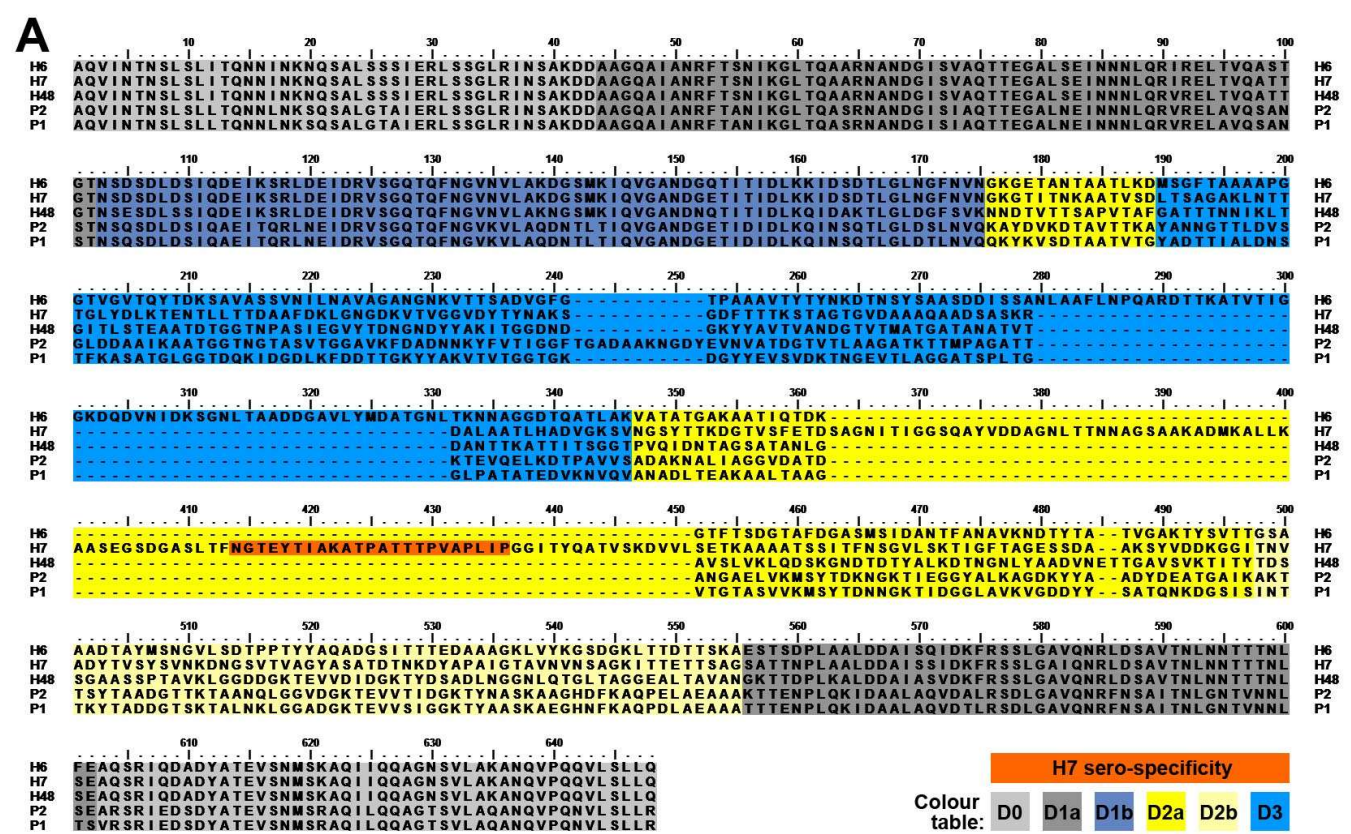

B H6 insertion: 52 aa
NLAAFLNPQARDTTKATVTIGGKDQ
DVNIDKSGNLTAADD GAVLYMDATG
NL
H7 insertion: 89aa
SAGNITIGGSQYYVDAGNLTTNNA
GSAAKADMKALLAASESDGSIT
FNGTEYTIAKATPATTT PVAPLIPG
GITYQATVSKDVVL

H48 insertion: 2aa ET

P2 insertion: 11aa TGADAAKNGDY

\section{SIDE}

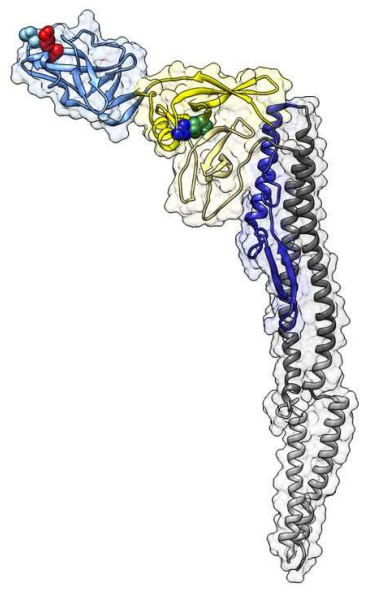

\section{TOP}

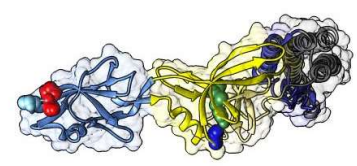

Figure S2. Protein sequence and structural differences between H6, H7, H48, P1 and P2 flagellins. (A) Pairwise structural alignments with P1 flagellin (PDB: 1UCU) were generated using the FFAS03 server from its PDB database. Alignments were then stitched together and presented in BioEdit v 7.2.0. Amino acids are coloured by structural domain, as defined by Yonekura et al. (9) and outlined in the colour table. This model is partially validated by the presence of the $\mathrm{H} 7$-serospecific region in the $\mathrm{H} 7$-specific structural insertion ((69), orange). (B) Amino acid sequences modelled to be structurally dissimilar to the P1 structural template, as determined by the alignment in (A). (C) Location of structural insertions in P1 flagellin indicated by spherically presented side-chains, colour-coded as in (B). The P1 structural model is presented coloured by structural domain as in (A), with top and side views, in USCF Chimera v 1.8 (70). 


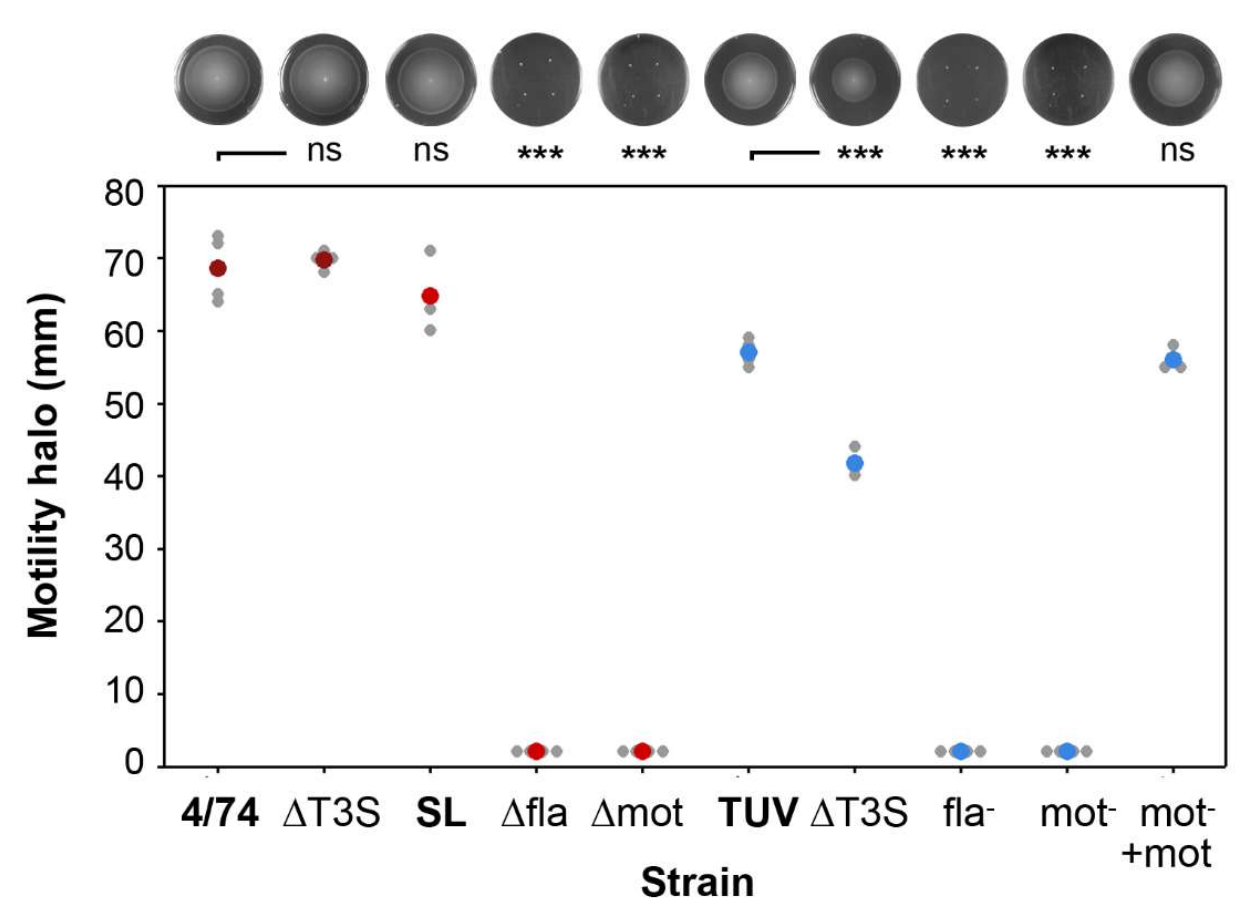

Figure S3. Motility S. Typhimurium and E. coli 0157:H7 strains used in haemolysis assays. Motility of strains used in Fig. 6 was measured by the radius of growth after inoculation into $0.3 \%(w / v)$ LB agar at RT for $36 \mathrm{~h}$. SL= SL1344. The top panel shows representative motility plates, and the bottom panel shows radii measurements from point of inoculation of four biological replicates. Statistical analyses of these are presented as 2-tailed homoscedastic students T-tests $\left(p \leq 0.0001={ }^{* * *}\right)$ against WT (4/74 or TUV93-0). 

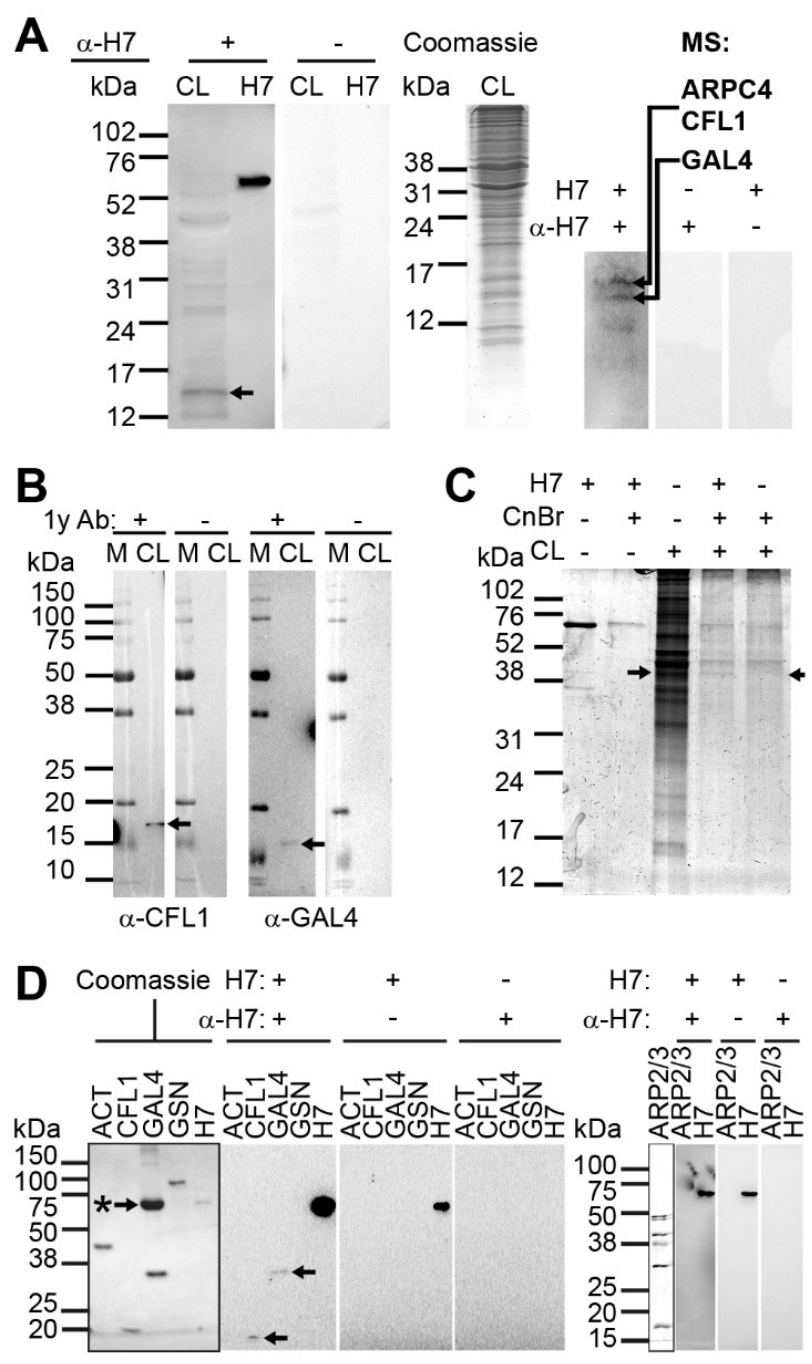

Figure S4. Binding substrates for $\mathrm{H} 7$ flagella present in bovine terminal rectum epithelial lysates. (A) Far-Western blot of primary bovine rectal epithelial cell lysates $(\mathrm{CL})$ probed with $\mathrm{H} 7$ flagella and H7-specific antibodies. Left-hand blots show one reacting band (arrow) resolved further (right) and the bands indicated were identified as Arp2/3 complex sub-unit 4 (ARPC4), cofilin-1 (CFL1) and galectin-4 (GAL4) by mass-spectrometry (MS). (B) Western-blots of primary bovine rectal epithelial cell lysates $(C L)$ confirmed the presence of CFL1 and GAL4 between 15-20 kDa with $\alpha$ CFL1 and a-GAL4 antibodies (arrows, Table S3). The size discrepancy of GAL4 can be explained by its degradation or processing within cell lysates, as has been observed previously $(71,72)$. (C) Pull-down of bovine $\beta$ actin from primary bovine rectal epithelial cell lysates (CL) by $\mathrm{H} 7$ flagella cross-linked to $\mathrm{CnBr}$ activated Sepharose beads. The cell lysates were prepared by freeze-thawing. Pre-cleared empty beads were used as a negative control (final lane). Arrows indicate 38-50 kDa protein bands in the coomassie-stained gel that were excised and identified as $\beta$-Actin (ACTB1) by MS. (D) Far-Western blots of $1 \mu \mathrm{g}$ purified human $\beta \gamma$-actin (ACT), recombinant human CFL1, recombinant human GAL4 and purified gelsolin (GSN) from bovine plasma with

negative control blots on the left, and $1 \mu \mathrm{g}$ purified ARPC4 from bovine brain with detection controls on the right, probed with $\mathrm{H} 7$ flagella and $\mathrm{H} 7$-specific antibodies as indicated. The $\sim 60 \mathrm{kDa}$ band indicated with an arrow marked with an $\left(^{*}\right)$ is $0.1 \%$ (w/v) BSA, a carrier protein for GAL4. $0.5 \mu \mathrm{g} \mathrm{H} 7$ was loaded as a positive detection control. Detected bands are indicated with arrows. Marker lane (M) sizes are in $\mathrm{kDa}$ on the left throughout. 
Movie S1. Co-localisation of E. coli 0157:H7 flagella with phalloidin on a bovine terminal rectal epithelial cell. A rotating three-dimensional projection of a confocal micrograph that has captured $E$. coli $0157: \mathrm{H} 7$ (green) flagella coincident with bovine primary rectal epithelial actin (red, Fig. 1A). Coincident staining of actin and $\mathrm{O} 157: \mathrm{H} 7$ is shown in yellow. The 3D projection was made and presented using NIH ImageJ software.

Movie S2. Tomographic slice of the flagellated S. Typhimurium within an epithelial cell. A view up and down through the $3 \mathrm{D}$ projection of the tomogramic slice shown in figure $5 \mathrm{~A} 1$, zooming in to the inset shown in figure 5A2. An anisotropic diffusion filter was applied to reduce noise.

Movie S3. Tomographic slice of the flagellated S. Typhimurium inside a membrane ruffle. A view up and down through the 3D projection of the tomogramic slice shown in figure 5B1, zooming in to the inset shown in figure 5B2. An anisotropic diffusion filter was applied to reduce noise.

Movie S4. Tomographic slice of the flagellated S. Typhimurium at the point of induced uptake into an epithelial cell shown in figure 5C. A view up and down through the 3D projection of the tomogramic slice shown in figure $5 \mathrm{C} 1$, with segmentation analysis of host cell membranes shown in red, zooming in to the inset shown in figure $5 \mathrm{C} 2$. An anisotropic diffusion filter was applied to reduce noise.

Table S1. Plasmids used or constructed in this study.

\begin{tabular}{|c|c|c|}
\hline Plasmid & Relevant features & Source \\
\hline pAJR145 & $A m p^{r}$, constitutively expressed eqfp & (73) \\
\hline plB307 & $\mathrm{Chl}{ }^{r}, \mathrm{Kan}^{r}, \mathrm{~T}^{\circ} \mathrm{C}^{\mathrm{s}}$ replication $\left(28^{\circ} \mathrm{C}\right)$, single copy & (55) \\
\hline pTOF25 & $\mathrm{Chl}$, Kan ${ }^{r}, \mathrm{~T}^{\circ} \mathrm{C}^{\mathrm{s}}$ replication $\left(28^{\circ} \mathrm{C}\right)$, single copy & (74) \\
\hline pEBW6 & pIB307; H7downB flank; H6 CDS; H7up flank & This study \\
\hline pEBW7 & plB307; H7downB flank; H7 CDS; H7up flank & This study \\
\hline pEBW5 & pWSK29 fli $C_{H 48}$ from E. coli K-12 MG1655 & (26) \\
\hline pTOFmotA & pTOF25; motA N flank; Kan'; motA C flank & This study \\
\hline
\end{tabular}


Table S2. Primer pairs used in this study. Annealing temperatures used indicated in bold.

\begin{tabular}{|c|c|c|c|}
\hline Product & Primer Name & Primer Sequence & Source \\
\hline $\begin{array}{l}\text { H7up } \\
\text { flank }\end{array}$ & 5'H7upF.Sacl & AAGAGCTCTATTGCCTGTGCCACTTCAC & $(26)$ \\
\hline $55^{\circ} \mathrm{C}$ & 3'H7upR.BamHI & AAGGATCCTAACTGAGACTGACGGCAAC & $(26)$ \\
\hline $\begin{array}{l}\text { H7down } \\
\text { B flank }\end{array}$ & H7downF3.BamHI & GGGGATCCCACCCGTCGGCTCAATCG & This study \\
\hline $55^{\circ} \mathrm{C}$ & 3'H7downR.Sall & AAGTCGACTTCGTATCGTCTCTGGTGGT & This study \\
\hline H7 CDS & 3'NtH7F2.BamHI & GGGGATCCCAATACGTAATCAACGACTTGC & This study \\
\hline $58^{\circ} \mathrm{C}$ & 5'CtH7R.BamHI & AAGGATCCTTAACCCTGCAGCAGAGACAG & This study \\
\hline H6 CDS & 3'NtH6F2.BamHI & GGGGATCCCAAAACGTAATCAACGACTTGC & $(22)$ \\
\hline $58^{\circ} \mathrm{C}$ & JTH11fliC.R.BamHI & CCGGATCCCTAACCCTGCAGCAGAGACAG & $(22)$ \\
\hline sacB & SacB 5' & GCAACTCAAGCGTTTGCGAAA & $(75)$ \\
\hline $55^{\circ} \mathrm{C}$ & SacB 3' & GGCTTGTATGGGCCAGTTAAG & $(75)$ \\
\hline $\begin{array}{l}\text { O157 } \\
\text { specific }\end{array}$ & O157F & CGGACATCCATGTGATATGG & (76) \\
\hline $55^{\circ} \mathrm{C}$ & O157R & TTGCCTATGTACAGCTAACC & $(76)$ \\
\hline $\begin{array}{l}\text { plB307 } \\
\text { insert }\end{array}$ & plB073-screen.F & CCTGTCCTACGAGTTGCATG & (65) \\
\hline $60^{\circ} \mathrm{C}$ & plB073-screen.R & GACTCCTGCATTAGGAAGCA & $(65)$ \\
\hline $\begin{array}{l}\text { FliC } \\
\text { locus }\end{array}$ & 5'H7upF.Sacl & AAGAGCTCTATTGCCTGTGCCACTTCAC & This study \\
\hline $55^{\circ} \mathrm{C}$ & 3'H7downR.Sall & AAGTCGACTTCGTATCGTCTCTGGTGGT & This study \\
\hline $\begin{array}{l}\text { MotA N } \\
\text { flank }\end{array}$ & No-motA & $\frac{\text { TTGCTGGTCTCGGTACCCGGG }}{\text { CGACAACATTAGCGGCACTGACTC }}$ & This study \\
\hline $50^{\circ} \mathrm{C}$ & Ni-motA & $\frac{\text { CGCTCTTGCGGCCGCTTGGAACGG }}{\text { GACATCATCCTTCCACTGTTGACC }}$ & This study \\
\hline $\begin{array}{l}\text { MotA C } \\
\text { flank }\end{array}$ & Co-motA & $\frac{\text { TCCCATTCGCCACCGGTCGAC }}{\text { CACGCTGTCACCTCGGTTCGGCTG }}$ & This study \\
\hline $50^{\circ} \mathrm{C}$ & Ci-MotA & $\frac{\text { CCGTTCCAAGCGGCCGCAAGAGCG }}{\text { ATGTGCGTGCGGTGAAAAATCCGC }}$ & This study \\
\hline
\end{tabular}


Table S3. Antibodies and stains used in this study.

\begin{tabular}{|c|c|c|}
\hline Primary Antibody & Details & Source \\
\hline$\alpha-\mathrm{H} 6$ & polyclonal rabbit IgG & Mast Assure \\
\hline$\alpha-\mathrm{H} 7$ & polyclonal rabbit lgG & Mast Assure \\
\hline$\alpha-F l i C(P 1)$ & polyclonal rabbit lgG & $\begin{array}{l}\text { Ariel Blocker Lab, } \\
\text { University of Bristol }\end{array}$ \\
\hline$\alpha-H i(P 1)$ & polyclonal rabbit IgG & Mast Assure \\
\hline$\alpha-H 2(P 2)$ & polyclonal rabbit IgG & Difco \\
\hline$\alpha-P 1+P 2$ & polyclonal rabbit lgG & Difco \\
\hline $\mathrm{\alpha}-\mathrm{O} 157: \mathrm{H} 7$ & polyclonal rabbit IgG & Mast Assure \\
\hline$\alpha-0157$ & monoclonal mouse lgG & Abcam \\
\hline $\mathrm{a}-\mathrm{O} 4$ & polyclonal rabbit IgG & Mast Assure \\
\hline a-cofilin-1 & monoclonal mouse lgG & AbDSeroTec \\
\hline a-galectin-4 & polyclonal goat lgG & R\&D \\
\hline Secondary Antibody & Details & Source \\
\hline a-rabbit IgG-HRP & polyclonal goat lgG & R\&D \\
\hline$\alpha$-goat lgG-HRP & polyclonal rabbit lgG & R\&D \\
\hline$\alpha$-mouse IgG-HRP & polyclonal donkey lgG & R\&D \\
\hline a-rabbit IgG-FITC & polyclonal goat lgG & Sigma \\
\hline$\alpha$-rabbit lgG-FITC & polyclonal goat lgG & R\&D \\
\hline a-rabbit lgG-10nm gold & polyclonal goat lgG & British Biocell Intl. \\
\hline a-rabbit lgG-AlexaFluor568 & polyclonal goat lgG & Molecular probes \\
\hline a-mouse lgG- AlexaFluor568 & polyclonal goat lgG & Molecular probes \\
\hline a-rabbit IgG- AlexaFluor594 & polyclonal goat lgG & Molecular probes \\
\hline Stains & & Source \\
\hline Phalloidin-Texas Red & & Invitrogen \\
\hline Phalloidin-AlexaFluor588 & & Molecular Probes \\
\hline Phalloidin-AlexaFluor647 & & Invitrogen \\
\hline Phalloidin-FITC & & Molecular Probes \\
\hline Phalloidin-TRITC & & Sigma \\
\hline DAPI & & Merck \\
\hline Wheat-germ agglutinin-Texas & & Invitrogen \\
\hline
\end{tabular}

